\title{
Estudo comparativo da qualidade da água da chuva coletada em telhado com telhas de concreto e em telhado verde para usos não potáveis
}

\author{
Comparative study of roof-harvested rainwater from \\ concrete tiles and green roof for non-potable usage
}

\begin{abstract}
Celimar Azambuja Teixeira
Marcel Aramis Budel

Karina Querne de Carvalho

Stella Maris da Cruz Bezerra

Enedir Ghisi

Celimar Azambuja Teixeira Universidade Tecnológica Federal do Curitiba -

\section{Resumo}

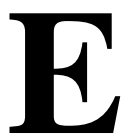

ste artigo apresenta uma comparação da qualidade da água da chuva coletada em telhado inclinado com telhas de concreto (residência 1) e cobertura plana e vegetada (residência 2 ), indicada como telhado verde Os objetivos desta investigação foram: (1) analisar a qualidade da água da chuva captada nas duas coberturas, com base nos parâmetros da NBR 15527 (ABNT, 2007) e (2) fazer acompanhamento da qualidade da água armazenada para verificar eficiência e comportamento dos dois telhados. Este estudo foi desenvolvido em Curitiba, PR, onde é obrigatório o aproveitamento da água da chuva em novas construções desde o ano de 2007. A água da chuva captada no telhado com telhas de concreto apresentou menores valores para turbidez e demanda química de oxigênio na maioria dos resultados (oito e sete amostras, respectivamente). $\mathrm{O}$ telhado verde contribuiu para a diminuição da acidez natural da água da chuva. Não foram atendidos os parâmetros microbiológicos estabelecidos na NBR 15527 (ABNT, 2007) em nenhuma das amostras coletadas. Apesar de a qualidade da água da chuva não atender todos os parâmetros indicados na NBR 15527 (ABNT, 2007), essa água vem sendo aproveitada nas residências para limpeza de calçadas, irrigação de jardim e descarga em bacias sanitárias, sem indicação de inconvenientes pelos moradores.
\end{abstract}

Marcel Aramis Budel Universidade Tecnológica Federal do Paraná Curitiba - PR - Brasil

Karina Querne de Carvalho Universidade Tecnológica Federal do

Paraná

Curitiba - PR - Brasil

Stella Maris da Cruz Bezerra Universidade Tecnológica Federal do Paraná

Curitiba - PR - Brasil

Enedir Ghisi Universidade Federal de Santa Catarina Florianópolis - SC - Brasil

Recebido em 24/12/15 Aceito em 22/10/16
Palavras-chaves: Água da chuva. Aproveitamento. Materiais para telhado. Telhas de concreto. Telhado verde. Anova.

\section{Abstract}

The article presents a comparison of rainwater quality for rainwater collected from a sloped roof with concrete tiles (residence 1) and from a flat green roof (residence 2). The aims of this study were: (1) to analyze the quality of roofharvested rainwater based on the guidelines of NBR 15527 (ABNT, 2007) and (2) to monitor the quality of stored rainwater in order to verify the efficiency and performance of both catchment systems. This study was conducted in the city of Curitiba, state of Paraná, Southern Brazil, where rainwater harvesting has been mandatory for new buildings since 2007. Rainwater collected from the roof with concrete tiles showed lower values for turbidity and chemical oxygen demand in most of the results (eight and seven samples, respectively). The green roof contributed to lowering the natural acidity of rainwater. The quality standards for coliforms established by NBR 15527 (ABNT, 2007) were not met in any of the samples collected. Despite the fact that not all parameters met the guidelines established by NBR 15527 (ABNT, 2007), the rainwater is being used for cleaning sidewalks, garden irrigation and toilet flushing, without complaints from its users.

Keywords: Roof-harvested rainwater. Roofing materials. Concrete tiles. Green roof. Anova.

TEIXEIRA, C. A.; BUDEL, M. A.; CARVALHO, K. Q. de; BEZERRA, S. M. da C.; GHISI, E. Estudo comparativo da qualidade 135 da água da chuva coletada em telhado com telhas de concreto e em telhado verde para usos não potáveis. Ambiente Construído, Porto Alegre, v. 17, n. 2, p. 135-155, abr./jun. 2017. ISSN 1678-8621 Associação Nacional de Tecnologia do Ambiente Construído. http://dx.doi.org/10.1590/s1678-86212017000200150 


\section{Introdução}

Na cidade de Curitiba, PR, os pedidos de alvará de construção devem atender às exigências indicadas pelo Decreto Municipal n. 212/2007 (CURITIBA, 2007). Dentre as exigências em vigor desde 2007 , em relação ao uso racional de água, é obrigatório:

(a) captar água da chuva para uso em atividades que não exijam água potável; e

(b) utilizar aparelhos e dispositivos redutores de consumo de água, como torneiras com arejadores e bacias sanitárias de volume reduzido.

O Programa de Conservação e Uso Racional da Água nas Edificações (Purae) foi o ponto de partida para criação do decreto supracitado (CURITIBA, 2003). Bezerra et al. (2009, 2010a, 2010b) apontaram a ausência de informações, no decreto em questão, sobre o monitoramento da qualidade da água da chuva nos reservatórios. Independentemente da ausência desse requisito, pesquisas foram realizadas entre 2008 e 2015 para monitorar a qualidade da água da chuva armazenada em três reservatórios de edifícios residenciais em Curitiba. Buzeti e Bezerra (2015, 2016) verificaram deterioração da qualidade da água armazenada apenas no reservatório do edifício onde não foi realizada limpeza anualmente.

Considerando que a qualidade da água da chuva armazenada depende das características do telhado por onde escoa, e é crescente a utilização de telhados verdes, é importante aprofundar o conhecimento sobre a qualidade da água da chuva após passar por diferentes tipos de telhados, incluindo uma cobertura vegetada. Esse conhecimento visa melhorar a avaliação das possibilidades de aproveitamento da água da chuva. Neste artigo é apresentado um comparativo da qualidade da água da chuva coletada em telhados de duas residências localizadas na cidade de Curitiba, sendo uma construída com telhado verde e a outra com telhado com telhas de concreto.

\section{Revisão bibliográfica \\ Qualidade da água da chuva}

A qualidade da água da chuva in natura varia de acordo com a região geográfica, considerando-se, por exemplo, a vegetação local, os espaços de zonas urbanas ou rurais, além da qualidade do ar. $\mathrm{Na}$ ausência de poluentes, o pH da água da chuva é de aproximadamente 5,7, indicando nível de acidez normal devido à formação de ácido carbônico
$\left(\mathrm{H}_{2} \mathrm{CO}_{3}\right)$, derivado do dióxido de carbono $\left(\mathrm{CO}_{2}\right)$, cuja presença é normal na atmosfera (JAQUES, 2005). Porém, as emissões poluentes lançadas na atmosfera, entre elas os gases provenientes da excessiva utilização de combustíveis fósseis, podem alterar o $\mathrm{pH}$ da água da chuva, fazendo com que, em alguns lugares, ocorram precipitações da chamada chuva ácida, quando o $\mathrm{pH}$ é reduzido para valores inferiores a 5,0. A chuva denominada ácida ocorre pela solubilização dos gases poluentes que estão na atmosfera, resultando na geração de ácidos mais fortes como, por exemplo, ácido nítrico $\left(\mathrm{HNO}_{3}\right)$ e ácido sulfúrico $\left(\mathrm{H}_{2} \mathrm{SO}_{4}\right)$.

Além dos aspectos previamente mencionados, a qualidade da água da chuva também varia em função do tipo do material utilizado na cobertura (GHAFFARIANHOSEINI et al., 2015; LEE; BAK; HAN, 2012; OLAOYE; OLANIYAN, 2012). Ou seja, a chuva in natura poderá sofrer alteração da sua qualidade de forma diferente, ao passar por uma cobertura com telhas de concreto, ou por uma cobertura vegetada (telhado verde) Outro aspecto que influencia a qualidade da água da chuva escoada pelos telhados é a possibilidade de carrear microrganismos, provenientes de fezes de animais acumuladas na cobertura, dentre eles pássaros, além de restos de plantas (folhas e galhos), muitas vezes em decomposição.

Na norma brasileira NBR 15527 (ABNT, 2007) da Associação Brasileira de Normas Técnicas (ABNT) são especificados parâmetros de qualidade para que a água da chuva coletada em telhados seja utilizada para usos não potáveis (Quadro 1).

Na cidade de São Paulo foram realizadas diversas pesquisas sobre a qualidade da água da chuva em amostras coletadas em reservatórios de sistemas de aproveitamento de água da chuva. Alguns desses resultados, obtidos de May (2009), estão apresentados na Tabela 1 .

Mais recentemente, para a cidade em questão neste artigo (Curitiba, PR), Buzeti e Bezerra (2015, 2016) verificaram, em amostras de água de chuva coletadas em três reservatórios de edifícios residenciais, que o $\mathrm{pH}$ apresentou resultados próximos da neutralidade, a cor aparente resultou inferior a $15 \mathrm{uH}$ e a turbidez inferior a 2,0 UNT. Além disso, a maioria das amostras indicou presença de coliformes totais e termotolerantes. Os reservatórios estavam em operação por aproximadamente sete anos. Em nenhuma das edificações selecionadas nos estudos de Buzeti e Bezerra $(2015,2016)$ existia telhado verde. 
Quadro 1 - Parâmetros de qualidade e frequência de monitoramento de água da chuva para usos não potáveis de acordo com a NBR 15527 (ABNT, 2007)

\begin{tabular}{|l|c|c|}
\hline PARÂMETRO & ANÁLISE & VALOR \\
\hline Coliformes totais (NMP) & Semestral & Ausência em 100 mL \\
\hline Coliformes termotolerantes (NMP) & Semestral & Ausência em 100 mL \\
\hline Cloro residual livre' $(\mathrm{mg} / \mathrm{L})$ & Mensal & 0,5 a 3,0 mg/L \\
\hline Turbidez (uT $\left.{ }^{2}\right)$ & Mensal & $<2,0 \mathrm{uT}$ \\
\hline $\begin{array}{l}\text { Cor aparente }\left(\mathrm{uH}^{3}\right) \\
\text { (caso não seja utilizado nenhum corante) }\end{array}$ & Mensal & $<5,0$ uT para usos menos restritivos \\
\hline $\begin{array}{l}\text { pH (deve prever ajuste para proteção das } \\
\text { redes de distribuição, caso necessário) }\end{array}$ & Mensal & $\begin{array}{c}\text { pH de } 6,0 \text { a 8,0 no caso de tubulação } \\
\text { de aço carbono ou galvanizado }\end{array}$ \\
\hline
\end{tabular}

Fonte: adaptado da NBR 15527 (ABNT, 2007).

Nota: ${ }^{1}$ No caso de serem utilizados compostos de cloro para desinfecção;

${ }^{2} \mathrm{uT}$ é a unidade de turbidez, também indicada como UNT; e

${ }^{3} \mathrm{uH}$ é a unidade Hazen.

Tabela 1 - Qualidade da água da chuva em diversas pesquisas

\begin{tabular}{|c|c|c|c|c|c|c|c|}
\hline \multirow{2}{*}{ Referência } & \multirow{2}{*}{ Local } & \multirow{2}{*}{ pH } & \multirow{2}{*}{$\begin{array}{c}\text { Cor aparente } \\
\text { (uC) }\end{array}$} & \multirow{2}{*}{$\begin{array}{l}\text { Turb* } \\
\text { (UNT) }\end{array}$} & \multirow{2}{*}{$\begin{array}{l}\text { SST** } \\
(\mathrm{mg} / \mathrm{L})\end{array}$} & CTT & CT \\
\hline & & & & & & \multicolumn{2}{|c|}{$(\mathrm{NMP} / 100 \mathrm{~mL})$} \\
\hline $\begin{array}{l}\text { Paiva et al. } \\
\text { (1997) }\end{array}$ & $\begin{array}{l}\text { São Paulo } \\
\text { (SP) }\end{array}$ & 4,5 & - & - & - & - & - \\
\hline $\begin{array}{l}\text { Rocha et al. } \\
(2003)\end{array}$ & $\begin{array}{l}\text { São Paulo } \\
\text { (SP) }\end{array}$ & 5,2 & - & - & - & - & - \\
\hline $\begin{array}{l}\text { Fornaro e } \\
\text { Gutz }(2000)\end{array}$ & $\begin{array}{l}\text { São Paulo } \\
\text { (SP) }\end{array}$ & 4,7 & - & - & - & - & - \\
\hline May (2004) & $\begin{array}{l}\text { São Paulo } \\
\text { (SP) }\end{array}$ & 6,7 & 25,2 & 0,9 & 1 & Presença & 54 \\
\hline
\end{tabular}

Fonte: adaptado de May (2009).

Nota: *Turbidez; **Sólidos suspensos totais; e -resultado não disponível.

\section{Qualidade da água da chuva ao escoar por telhados verdes}

Telhados verdes, também chamados telhados vegetados, podem ser definidos de forma bem simplificada como coberturas de edificações constituídas de laje impermeabilizada, seguida de camada drenante e substrato, onde são plantadas espécies vegetais de pequeno e médio porte. Os componentes do telhado verde são definidos a partir de critérios do projeto arquitetônico em questão e da tipologia do telhado. A vegetação é selecionada em função da tipologia, com base em aspectos estéticos, seguindo as características climáticas regionais. $\mathrm{O}$ telhado verde foi desenvolvido para promover o crescimento de vegetação na cobertura de edificações, com finalidades estéticas, ambientais ou até mesmo econômicas (HASHEMI; MAHMUD; ASHRAF, 2015; RAZZAGHMANESHA; BEECHAMA; SALEMIBA, 2016; TASSI et al., 2014; VIJAYARAGHAVAN, 2016).

Alguns estudos da qualidade da água escoada em telhados verdes indicaram variações significativas nos resultados de $\mathrm{pH}$ e da concentração de nutrientes e metais pesados, em função das diferenças na construção e manutenção dos telhados, e também dos aspectos da qualidade do ar no local (BERNDTSSON, 2010). A qualidade da água da chuva captada em telhados verdes é dependente de vários aspectos, dentre eles: (1) característica do telhado (espessura da camada de solo, composição do solo, vegetação e tipo de drenagem), (2) idade do telhado e (3) frequência da manutenção do telhado, incluindo fertilização, substituição de plantas e replantio. A água da chuva escoada a partir do telhado verde pode apresentar nutrientes lixiviados da vegetação e substrato, microrganismos e ter a cor alterada, portanto pode ser indicada a utilização de algum tipo de filtro, sem posterior desinfecção (VIJAYARAGHAVAN, 2016). Além disso, conforme citado anteriormente, a qualidade do ar também influencia a qualidade da água da chuva, tal como as emissões resultantes do tráfego local e os aspectos da área circundante (industrial, residencial ou comercial).

A qualidade da água da chuva após percolação a partir do telhado verde pode tanto melhorar quanto piorar. Castro (2011) destacou que a presença da 
cobertura verde em terraços e telhados aumenta os valores de sólidos totais, fósforo total, nitrogênio, nitrato, turbidez, DBO, além de tornar o $\mathrm{pH}$ mais alcalino (próximo a 8). Vijayaraghavan (2016) indica que o telhado verde pode agir como um filtro de material particulado, porém ao mesmo tempo liberar nutrientes e metais pesados na água da chuva pela lixiviação.

Diante disso, ainda há divergência de opinião se o telhado verde contribui ou não para a melhoria da qualidade da água da chuva para posterior aproveitamento para fins não potáveis. Dessa forma, a condução de estudos locais é imprescindível para aumentar o leque de conhecimento sobre os aspectos de telhados verdes a partir de características climáticas e de urbanização específicas.

Neste artigo a qualidade da água da chuva captada em dois telhados foi avaliada para posterior aproveitamento em usos não potáveis. A pesquisa foi realizada em duas residências localizadas na zona urbana de Curitiba, comparando um sistema com telhas de concreto e outro com telhado verde. Coberturas vegetadas podem ser consideradas terraços verdes quando ocorre alguma circulação de pessoas ou animais. A cobertura da residência estudada neste trabalho tem uma área de passarela, mas ocorre pouca circulação de pessoas e não há nenhum animal doméstico na residência. Por esse motivo, optou-se pelo termo telhado verde, por ser mais comum na literatura e em função da pouca circulação dos moradores.

\section{Material e métodos}

\section{Área de Estudo}

O estudo foi realizado em duas residências distantes $410 \mathrm{~m}$ entre si, situadas no bairro de
Santa Felicidade, na região noroeste da cidade de Curitiba, com altitude média de 934,6 $\mathrm{m}$ acima do nível do mar.

$\mathrm{Na}$ cidade de Curitiba, o clima é temperado (ou subtropical) úmido, mesotérmico, sem estação seca, com verões frescos e invernos com geadas frequentes e ocasionais precipitações de neve, tipo $\mathrm{Cfb}$, de acordo com classificação de Köppen (MAACK, 1981).

As residências estão inseridas em condomínios residenciais fechados com vegetação em seus entornos e características similares de vegetação e urbanização. As residências estão distantes de rodovias com fluxo intenso de veículos e do distrito industrial de Curitiba (Figura 1).

A cobertura da residência 1 (Figura 2a) corresponde a um telhado com inclinação de 50\%, composto de telhas de concreto planas (Figura 2b). A área de captação de água da chuva tem $65 \mathrm{~m}^{2}$, correspondente a uma das duas águas do telhado. A água da chuva, após escoar pelo telhado de concreto, é coletada por uma calha de zinco com pintura em esmalte sintético. Em seguida, essa água é transportada por um condutor de mesmo material até o nível do solo (Figura 3a), onde há um filtro do tipo 3P Technik_VF1 (Figura 3b). A função desse filtro é a retenção de materiais grosseiros, como folhas, galhos, dentre outros. Após passagem pelo filtro, a água é encaminhada para um reservatório inferior, enterrado, de 2.800 litros, de polietileno de alta densidade (Pead) para armazenamento e posterior uso. Esse reservatório será indicado neste estudo como TC.

Figura 1 - Localização das residências em estudo

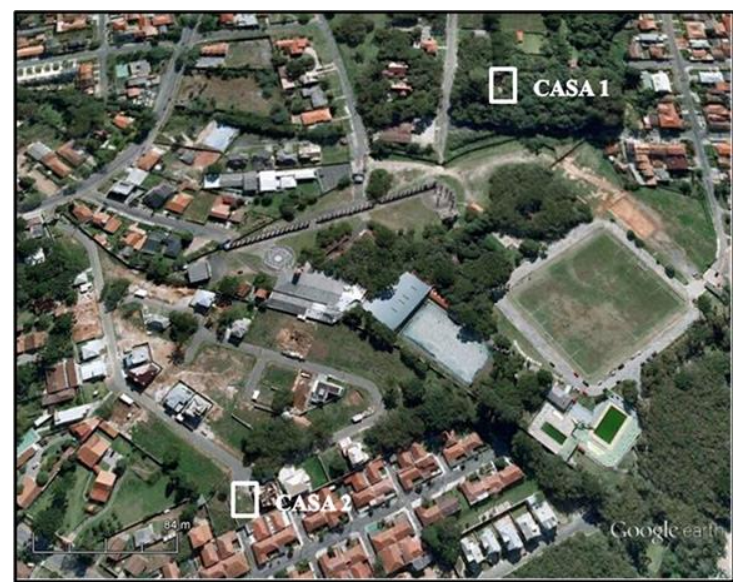

Fonte: adaptado de Google Earth (2013).

Nota: a indicação exata das residências não será fornecida por questões de confidencialidade.

138 Teixeira, C. A.; Budel, M. A.; Carvalho, K. Q. de; Bezerra, S. M. da C.; Ghisi, E. 
Figura 2 - Vista frontal e detalhe das telhas de concreto da residência 1

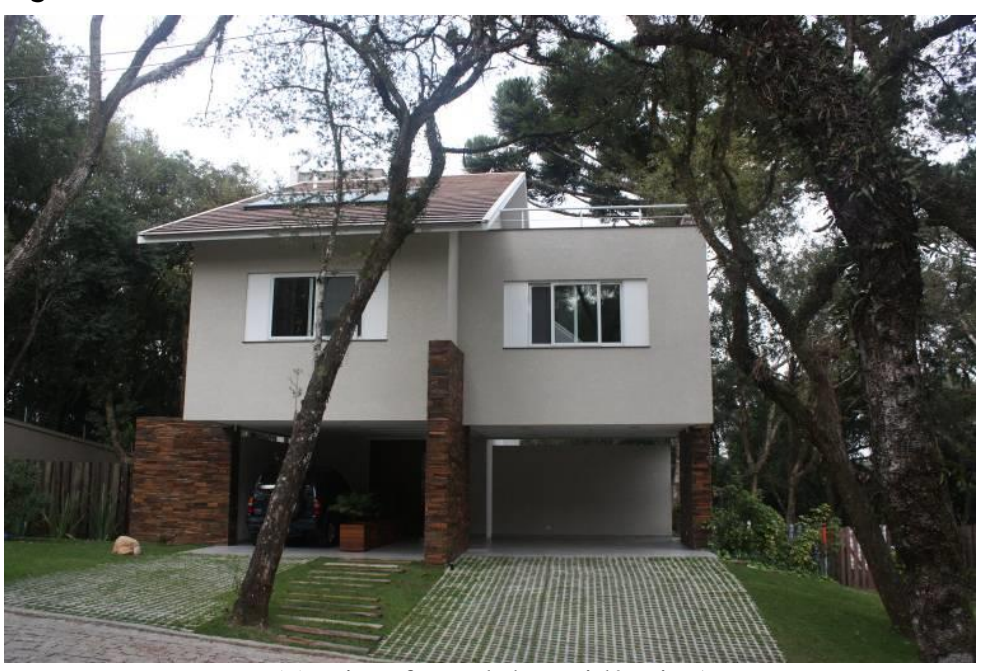

(a) Vista frontal da residência 1

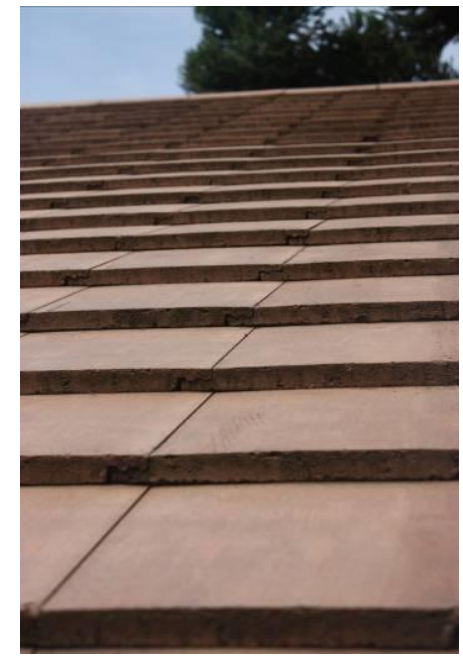

(b) Detalhe das telhas de concreto

Fonte: Budel (2014).

Figura 3 - Condutor de zinco e detalhe do filtro 3P Technik_VF1 na residência 1

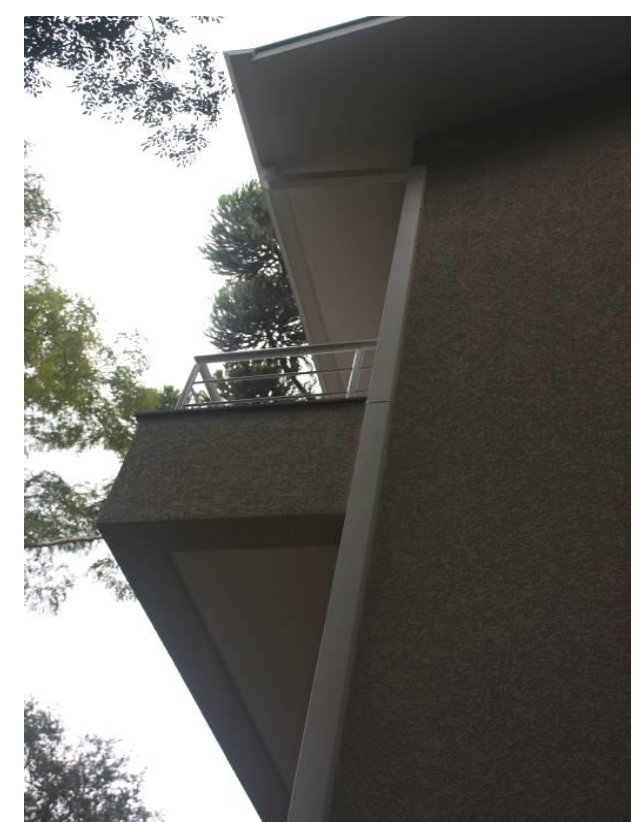

(a) Condutor de zinco na residência 1

Fonte: Budel (2014).

Na residência 1, a água da chuva é utilizada para limpeza de calçadas nas áreas externas e irrigação de jardim. A instalação hidráulica exclusiva desse sistema de aproveitamento de água de chuva contém torneiras de acionamento restrito com chave destacável para que não haja risco de utilização indevida. O sistema de distribuição da água da chuva armazenada nessa residência conta com eletrobomba e pressostato, que aciona o funcionamento da bomba quando é verificada variação de pressão ao abrir uma das duas torneiras que compõem o sistema (Figura 4).
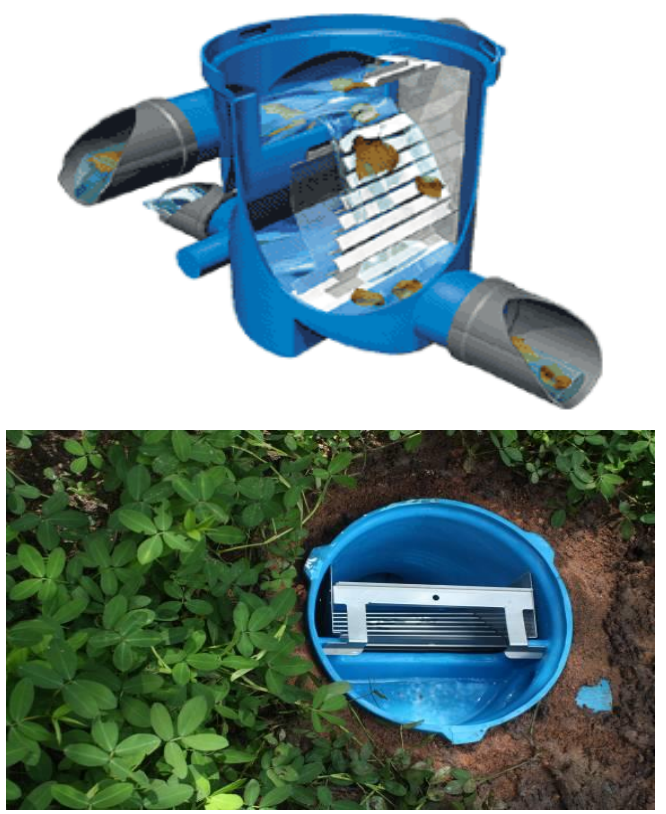

(b) Detalhe do filtro 3P Technik_VF1

$\mathrm{Na}$ outra residência em estudo (residência 2), a cobertura é composta de um telhado vegetado com $77 \mathrm{~m}^{2}$ de área de captação. Esse telhado verde foi finalizado em maio de 2011. As coletas de amostra de água de chuva foram iniciadas em maio de 2013, ou seja, o telhado verde estava com dois anos quando esta pesquisa foi iniciada.

A água da chuva após passagem pelo telhado verde é conduzida por dois condutores verticais de PVC com $100 \mathrm{~mm}$ de diâmetro até um reservatório inferior em concreto, enterrado, com volume de 
1.500 litros. Esse reservatório será indicado neste artigo como TVI. O sistema de aproveitamento da água da chuva nessa residência contempla uma eletrobomba para recalque da água do reservatório inferior para dois filtros de membrana instalados em série, de $200 \mu \mathrm{m}$ e $50 \mu \mathrm{m}$, respectivamente, antes de seguir para o reservatório superior, de Pead, com volume de 1.000 litros, localizado na cobertura acima do nível do telhado verde (Figura 5). Esse reservatório será indicado como TVS.

A laje da cobertura foi impermeabilizada para construção do telhado verde. Sobre essa impermeabilização foi colocada uma camada de 15 $\mathrm{cm}$ de terra e $5 \mathrm{~cm}$ de argila expandida responsável pela drenagem do sistema, sobreposta por uma manta geotêxtil Bidim 150 gramas, compondo a

Figura 4 - Componentes do sistema na residência 1

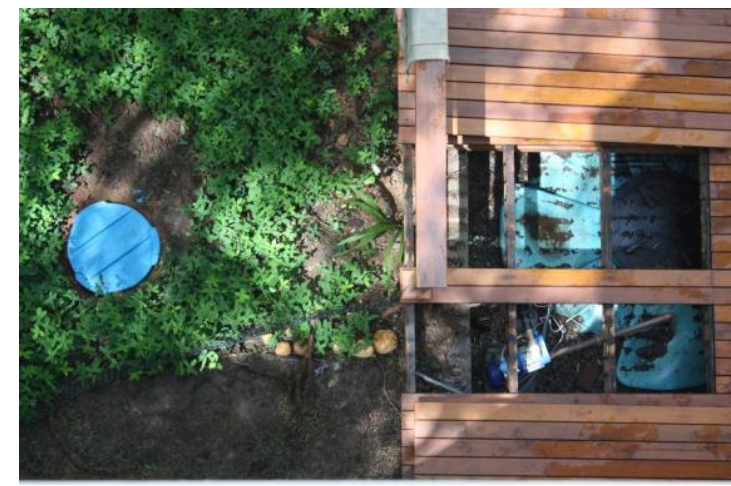

(a) Vista superior do filtro e reservatório enterrado (TC)

Fonte: Budel (2014).

Figura 5 - Componentes do sistema na residência 2

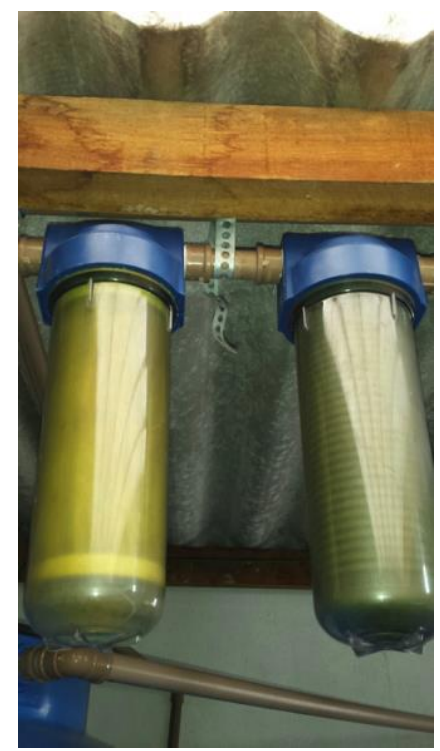

(a) Filtros de membrana na entrada do TVS Fonte: Budel (2014). camada filtrante, na qual a água é conduzida para dois condutores verticais, sendo um de cada lado do telhado verde e posicionado na parte da frente do telhado. Além disso, foi usada terra comum para jardinagem, comercializada nas lojas do ramo (Figura 6) como substrato da camada vegetada plantada com grama-esmeralda (Zoysia japonica).

Embora a estrutura da cobertura permita acesso (área de passarela), ocorre circulação limitada de pessoas e não há nenhum animal doméstico na residência. Portanto, foram adotados os parâmetros de caracterização de água da chuva conforme a norma ABNT NBR 15527:2007 (ABNT, 2007), que serão abordados posteriormente.

Na Figura 7 é apresentado um corte esquemático dos elementos do telhado verde.

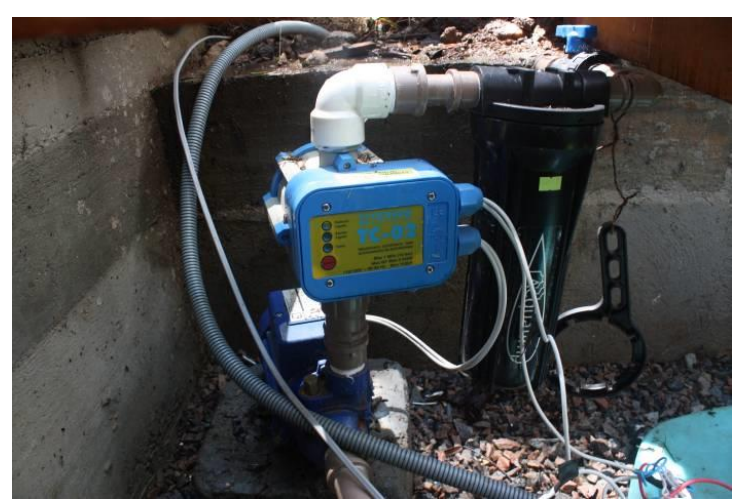

(b) Detalhe da eletrobomba e pressostato

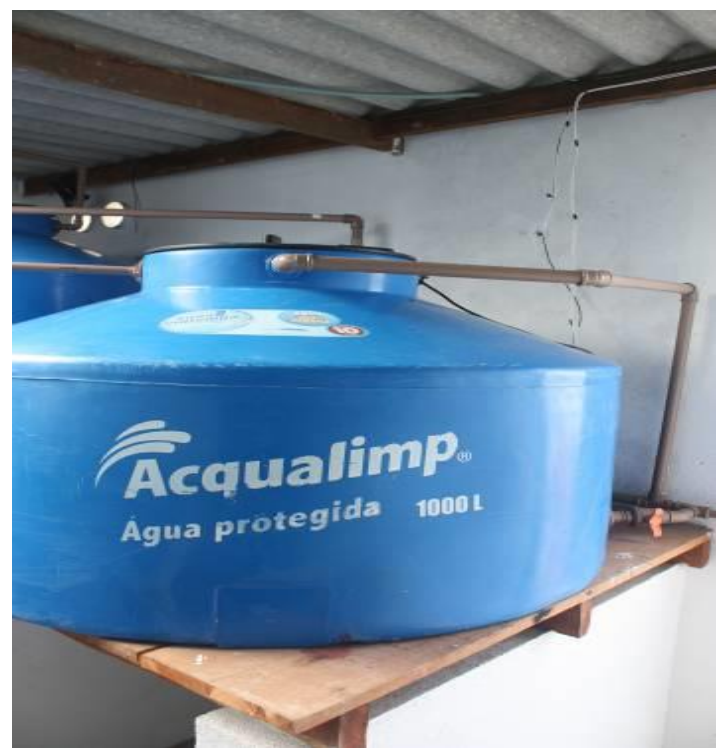

(b) Reservatório superior

140 Teixeira, C. A.; Budel, M. A.; Carvalho, K. Q. de; Bezerra, S. M. da C.; Ghisi, E. 
Figura 6 - Detalhes da laje de cobertura da residência 2

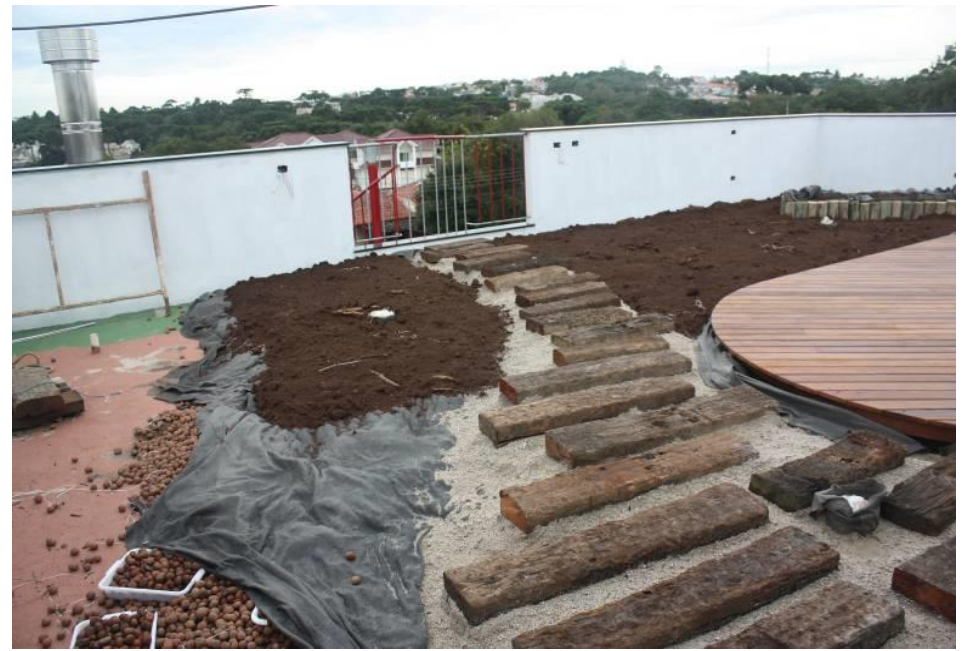

(a) Camadas do telhado verde em execução com detalhe da laje impermeabilizada

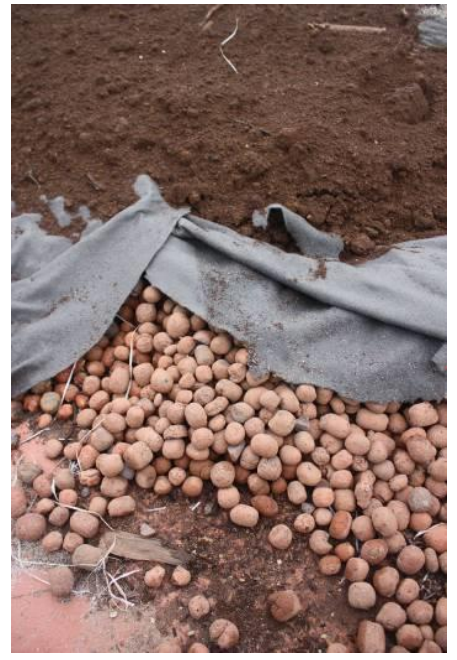

(b) Detalhe da argila expandida, manta geotêxtil e camada de terra

Fonte: Budel (2014).

Figura 7 - Corte esquemático do telhado verde, com seus componentes

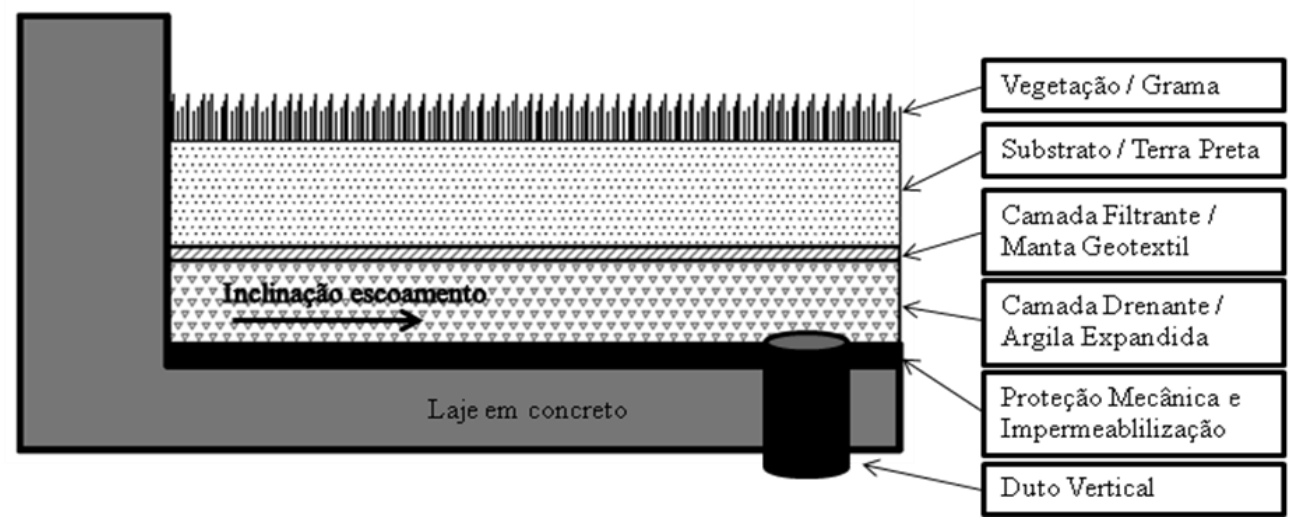

Fonte: Budel (2014).

Nessa residência, a água da chuva é utilizada para abastecimento de cinco bacias sanitárias, para limpeza externa e rega de jardim com distribuição da água em dois pontos externos. O sistema é dependente da rede pública de água potável para que o abastecimento de água para as bacias sanitárias não seja prejudicado em períodos de estiagem.

Quando o nível da água da chuva está baixo, a eletrobomba instalada no interior do reservatório superior aciona a entrada da água proveniente da rede pública de abastecimento vindo de um reservatório exclusivo de água potável localizado ao lado do reservatório superior (Figura 5b). Portanto, o reservatório superior pode receber contribuição de duas fontes, sendo uma do reservatório inferior de água da chuva e outra do reservatório de água potável. Há apenas uma saída da água do reservatório superior para uso não potável por gravidade, para abastecer as torneiras de limpeza externa e bacias sanitárias.

Para não ocorrer contaminação cruzada da água potável com a água da chuva, as entradas das alimentações estão afixadas em alturas diferentes, configurando uma separação atmosférica; a entrada da água potável fica em altura superior e acima do extravasor. Portanto, mesmo em caso de transbordo, não há risco de entrada da água de chuva no ponto de alimentação da água potável.

\section{Pontos de amostragem}

Neste estudo foram feitas caracterizações qualitativas da água da chuva (coletada diretamente da atmosfera, in natura) e da água coletada nos reservatórios das residências 1 e 2 . 
As coletas da água de chuva in natura foram realizadas por meio de um recipiente de vidro previamente esterilizado com água fervente $\mathrm{e}$ lavado com água destilada, após cada coleta. Esse recipiente era colocado na haste de madeira e ficava exposto às intempéries para recebimento da próxima precipitação. Portanto, a qualidade da água armazenada ficava sujeita a possíveis interferências devido à deposição de poeira, ao pouso de aves, dentre outros. O ponto de coleta da água da chuva in natura está localizado em local descoberto a 1,20 $\mathrm{m}$ do solo, nas proximidades da residência 1. Após os eventos de precipitação, as amostras eram retiradas e levadas para análise junto com as amostras dos outros pontos.

Na residência 1, a coleta das amostras de água da chuva foi feita em uma torneira existente no reservatório, após passagem pelo telhado com telhas de concreto e pelo filtro do tipo $3 \mathrm{P}$ Technik_VF1.

Na residência 2, a coleta das amostras de água da chuva, após passagem pelo telhado verde, foi realizada em uma torneira externa existente no reservatório inferior e em uma torneira existente no reservatório superior, após passagem pelos filtros de membrana. É importante salientar a possibilidade de implicações diretas nos resultados, pois a amostra poderá estar composta da mistura da água de chuva e da água potável, visto que os reservatórios para água de chuva podem receber água potável em situações de estiagem.

A determinação do volume dos reservatórios inferior e superior, quando da época do projeto dessa residência, foi feita com base no Decreto Municipal de Curitiba n. 293/2006, no qual é estabelecido o volume mínimo de 500 L (CURITIBA, 2006)

Foram realizadas comparações dos valores médios dos parâmetros de qualidade da água das amostras coletadas com os valores de referências da norma NBR 15527 (ABNT, 2007). Os parâmetros analisados foram turbidez (UNT), potencial hidrogeniônico $(\mathrm{pH})$, coliformes totais $(\mathrm{CT})$ e coliformes termotolerantes (CTT, Escherichia coli). Essa norma foi utilizada por ser a regulamentação existente no Brasil para os sistemas de aproveitamento de água da chuva em coberturas no meio urbano.

A fim de melhor caracterizar a qualidade da água amostrada, temperatura da água, oxigênio dissolvido (OD), amônia $\left(\mathrm{NH}_{3}\right)$, nitrito $\left(\mathrm{NO}_{3}{ }^{-}\right)$, nitrato $\left(\mathrm{NO}_{2}^{-}\right)$, fosfato $\left(\mathrm{PO}_{4}^{-3}\right)$ e demanda química de oxigênio (DQO) também foram determinados.
A temperatura foi determinada por influenciar de forma significativa os demais parâmetros de qualidade da água. $\mathrm{O}$ oxigênio dissolvido (OD) e a demanda química de oxigênio (DQO) foram avaliados por se tratarem de indicadores que representam a qualidade da água em termos de concentração de matéria orgânica. Amônia, nitrito e nitrato foram caracterizados por indicarem índices que estão relacionados com as questões de solo e vegetação e poderiam ser afetados diretamente pelo telhado verde, bem como o fosfato pela relação com a fertilização do solo e, portanto, com o telhado verde. Para análises de comparação, o fosfato também foi medido no telhado com telhas de concreto.

Todas as análises foram realizadas de acordo com procedimentos descritos no Standard Methods for Examination of Water \& Wastewater (EATON et al., 2005) em triplicata.

O índice de Langelier (IL) também é um parâmetro interessante para ser analisado em sistemas de aproveitamento de água da chuva. O IL indica o grau de saturação de carbonato de cálcio na água e poder de incrustação e corrosividade. Neste artigo o IL não foi inicialmente incluído nos parâmetros selecionados e por isso não foi avaliado.

Após cada evento de chuva, as amostras de água do TVI foram coletadas a aproximadamente $10 \mathrm{~cm}$ abaixo da superfície da água, armazenadas em frascos previamente esterilizados, mantidas em gelo de acordo com procedimentos descritos na norma NBR 9898 (ABNT, 1987) e transportadas ao Laboratório de Saneamento da Universidade Tecnológica Federal do Paraná, campus Curitiba, sede Ecoville. As amostras foram homogeneizadas antes de cada coleta nos reservatórios das residências e antes da realização dos procedimentos analíticos. As coletas foram realizadas durante o período de 17 de maio a 3 de dezembro de 2013, com uma coleta mensal, totalizando oito coletas. As coletas foram realizadas nos dias 17 de maio, 26 de junho, 22 de julho, 14 de agosto, 2 de setembro, $1^{\underline{0}}$ de outubro, 17 de outubro, 12 de novembro e 3 de dezembro de 2013 .

Temperatura, turbidez, OD e $\mathrm{pH}$ foram determinados em oito coletas, iniciadas no dia $17 / 05 / 2013$, e amônia, nitrito, nitrato, fosfato e DQO em sete coletas, iniciadas em 26/06/2013, devido a problemas no destilador de nitrogênio. As determinações de coliformes totais e termotolerantes foram feitas em nove coletas em laboratório terceirizado, iniciando no dia $17 / 05 / 2013$. No dia 03/12/2013 só foi possível realizar coleta para a análise microbiológica. 
Para a execução das análises realizadas in loco foram utilizados termômetro digital para medição de temperatura da água, turbidímetro Policontrol AP 2000 para quantificação da turbidez, medidor de oxigênio dissolvido Lutron DO 5519 e pHmetro digital pHTech no momento das coletas. As determinações da amônia, nitrito, nitrato, fosfato e demanda química de oxigênio (DQO) foram feitas utilizando fotômetro multiparâmetro de bancada Hanna HI 83099. Coliformes totais (método SM $9221 \mathrm{~B} / \mathrm{C}$ e E) e termotolerantes (Escherichia coli, método SM $9221 \mathrm{~F}$ ) foram determinados em laboratório terceirizado em Curitiba, para o qual as amostras foram imediatamente levadas após cada coleta. As análises foram executadas segundo metodologias estabelecidas no Standard Methods for Examination of Water \& Wastewater (EATON et al., 2005).

\section{Pluviometria}

Os índices pluviométricos para este estudo foram obtidos a partir da estação meteorológica da Superintendência de Desenvolvimento de Recursos Hídricos e Saneamento Ambiental (SUDERHSA), que atualmente recebe o nome de Instituto Águas do Paraná. Os dados foram coletados para os anos de 1982 até 2013 e referem-se à Bacia do Rio Iguaçu, na estação denominada Prado Velho PUC. Com base nesses dados, foram utilizadas as médias mensais e média anual histórica para o período de 1982 a 2014. Assim, a precipitação média anual é de $1492 \mathrm{~mm}$.

\section{Análise de dados}

Estatísticas descritivas foram usadas para descrever os dados coletados nos quatro pontos: $\mathrm{N}$ (in natura), TC (telhado de concreto reservatório), TVI (telhado verde - reservatório inferior) e TVS (telhado verde - reservatório superior). Medidas de tendência central e dispersão, usando inferência estatística e nível de significância de 5\%, foram realizadas. A inferência estatística foi realizada usando teste paramétrico Anova. O teste Tukey post-hoc foi usado para comparação das médias.

Os dados experimentais, obtidos com as determinações físico-químicas e microbiológicas, foram apresentados em gráficos com linha. Os pontos foram ligados por linhas suaves com o objetivo de facilitar a visualização, mas não foram realizadas medições intermediárias, nem efetuados ajustes nas curvas. Portanto, os valores intermediários entre dois pontos consecutivos não representam interpolação de valores.

\section{Resultados}

\section{Pluviometria}

Na Tabela 2 são apresentados os valores das precipitações médias mensais.

Na Figura 8 pode-se observar que o ano de 2013 foi bastante atípico em relação aos valores observados na série histórica da pluviometria da região, com volume de chuva acentuado no período do inverno, quando normalmente ocorrem menos eventos pluviométricos. No mês de junho foi verificado maior número de dias de chuva (12 dias) e com maior pluviometria mensal (324 mm), em comparação aos demais meses avaliados no estudo.

Os eventos de chuva diários com lâmina de água menor ou igual a $2 \mathrm{~mm}$ não foram considerados devido à precisão do pluviômetro utilizado neste estudo. Por esse motivo, esse volume de chuva foi descartado. O valor encontrado para a máxima lâmina de chuva foi registrado no dia 21/06/2013.

$\mathrm{Na}$ Tabela 3 são apresentadas as datas das coletas, o número de dias entre as coletas, a pluviometria diária $(\mathrm{mm} / \mathrm{dia})$, a pluviometria acumulada entre as coletas ( $\mathrm{mm})$, os dias de chuvas entre as coletas e o número de dias sem chuva avaliados durante a realização deste estudo. Tais itens foram levantados porque se houver vários dias sem chuva haverá interferência na concentração de poluentes na atmosfera e consequentemente na qualidade da chuva in natura.

As coletas das amostras in natura foram feitas manualmente, após o término da chuva. O maior período de estiagem foi em agosto, quando foram observados dezesseis dias sem chuva. O segundo maior período de estiagem foi em novembro, após sete dias sem chuva.

Tabela 2 - Valores de precipitações médias mensais entre 1982 a 2013

\begin{tabular}{|c|c|c|c|c|c|c|c|c|c|c|c|c|}
\hline Meses & JAN & FEV & MAR & ABR & MAI & JUN & JUL & AGO & SET & OUT & NOV & DEZ \\
\hline $\begin{array}{l}\text { Precipitação } \\
\text { Média (mm) }\end{array}$ & 189,89 & 165,65 & 132,57 & 91,92 & 100,37 & 101,93 & 103,95 & 73,76 & 135,60 & 137,38 & 110,68 & 148,03 \\
\hline
\end{tabular}


Figura 8 - Pluviometria diária no período de 5 de maio a 3 de dezembro de 2013

\section{Pluviometria diária (mm)}

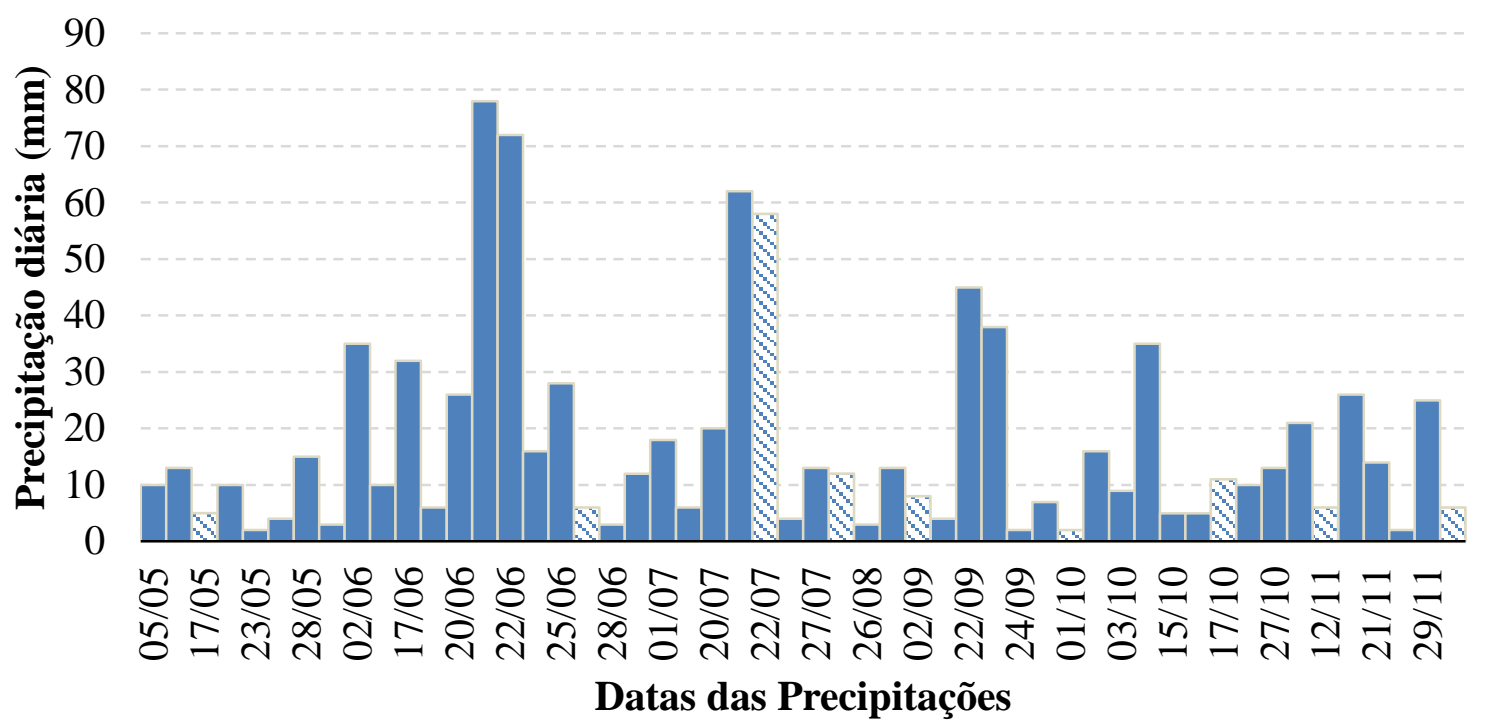

Nota: *os dias destacados em hachurado correspondem às datas de coleta das amostras.

Tabela 3 - Comparativo pluviométrico das chuvas no local do estudo

\begin{tabular}{c|c|c|c|c|c}
\hline $\begin{array}{c}\text { Data das } \\
\text { coletas }\end{array}$ & $\begin{array}{c}\text { Dias entre } \\
\text { coletas }\end{array}$ & $\begin{array}{c}\text { Pluviometria } \\
(\mathbf{m m} / \mathbf{d i a})\end{array}$ & $\begin{array}{c}\text { Pluviometria } \\
\text { acumulada entre } \\
\text { coletas (mm) }\end{array}$ & $\begin{array}{c}\text { Dias de chuva } \\
\text { entre as coletas } \\
\text { (dias) }\end{array}$ & $\begin{array}{c}\text { Dias sem chuva } \\
\text { anteriores ao } \\
\text { dia da coleta }\end{array}$ \\
\hline $05 / 05 / 2013$ & \multicolumn{5}{|l}{} \\
\hline $17 / 05 / 2013$ & 12 & 5 & 28 & 3 & 0 \\
\hline $26 / 06 / 2013$ & 41 & 6 & 343 & 15 & 0 \\
\hline $22 / 07 / 2013$ & 25 & 58 & 179 & 7 & 0 \\
\hline $14 / 08 / 2013$ & 23 & 12 & 17 & 2 & 16 \\
\hline $02 / 09 / 2013$ & 22 & 8 & 36 & 4 & 2 \\
\hline $01 / 10 / 2013$ & 27 & 2 & 98 & 6 & 0 \\
\hline $17 / 10 / 2013$ & 16 & 11 & 81 & 6 & 7 \\
\hline $12 / 11 / 2013$ & 26 & 6 & 44 & 3 & 3 \\
\hline $03 / 12 / 2013$ & 22 & 6 & 79 & 6 & \\
\hline
\end{tabular}

Nota: nos dias de coleta nos reservatórios, mas sem eventos de chuva, as coletas de água in natura $(\mathrm{N})$ foram realizadas no evento mais próximo, podendo ser no dia anterior ou seguinte. Para correta interpretação dos dados da Tabela $1 \mathrm{faz}$ se necessária a análise da Figura 8, na qual são apresentadas a pluviometria e as datas dos eventos de chuva.

\section{Temperatura}

A variação da temperatura de $8^{\circ} \mathrm{C}$ a $26^{\circ} \mathrm{C}$ foi verificada nas amostras de água coletadas na residência 2, no reservatório superior, construído acima do telhado verde, e, portanto, mais exposto às alterações climáticas. A temperatura da água da chuva in natura, também teve variação mais acentuada em comparação àquelas observadas nos outros dois pontos de coleta, nos reservatórios inferiores das residências 1 e 2, os quais tendem a ser mais estáveis quanto à variação da temperatura (Figura 9).
A inexistência de diferenças significativas nos resultados médios de temperatura (p-valor 0,9374) entre as amostras coletadas foi identificada pela Anova. As maiores variações no valor médio da temperatura foram de $1,13^{\circ} \mathrm{C}\left(16,38-15,25^{\circ} \mathrm{C}\right)$ entre $\mathrm{N}$ e $\mathrm{TC}, 1,0^{\circ} \mathrm{C}\left(16,38-15,38^{\circ} \mathrm{C}\right)$ entre $\mathrm{N}$ e TVI, $0,88^{\circ} \mathrm{C}\left(16,13-15,25^{\circ} \mathrm{C}\right)$ entre TC e TVS, e $0,75^{\circ} \mathrm{C}\left(16,13-15,38^{\circ} \mathrm{C}\right)$ entre TVS e TVI. Os valores máximos observados foram de $24,0^{\circ} \mathrm{C}$ no $\mathrm{N}, 20,0^{\circ} \mathrm{C}$ no $\mathrm{TC}$ (variação de $4,0^{\circ} \mathrm{C}$ ), $26^{\circ} \mathrm{C}$ no TVS e $19^{\circ} \mathrm{C}$ no TVI. O valor mínimo de temperatura foi de $8,0^{\circ} \mathrm{C}$ no TVS. 


\section{Turbidez}

Os resultados dos parâmetros físico-químicos podem ser influenciados pelo período de estiagem e pelo volume de chuva ocorrido. Ambos interferem nas concentrações dos poluentes atmosféricos que consequentemente são removidos do ar para a água da chuva.

$\mathrm{Na}$ Figura 10 é possível verificar variação da turbidez média de 1,56 a 9,86 UNT entre os pontos coletados, com valor mínimo de 0,02 UNT nas amostras do TC e com valor máximo de 18,5 UNT nas amostras do TVI no dia 22/07/2013, que pode estar relacionado à maior pluviometria registrada nesse dia. O valor máximo de 31,8 UNT obtido na amostra $\mathrm{N}$ pode estar relacionado a algum erro de leitura. Valores similares foram obtidos por Morquecho, Pitt e Clark (2005) de 2,0 a 22 UNT em telhados convencionais, que também indicaram maiores concentrações de sólidos nos telhados verdes quando comparados aos telhados convencionais.

Morgan, Celik e Retzlaff (2013) também verificaram maior turbidez nas amostras dos telhados verdes investigados durante o primeiro momento das chuvas (550 UNT) seguida de redução após um segundo evento de chuva (50 UNT). Contudo, nas amostras coletadas no TVS foi possível observar menor valor de turbidez naquela data (22/07/2013), o que pode estar relacionado à filtração exercida pelos filtros de membranas instalados. O mesmo comportamento foi verificado nas amostras coletadas no reservatório da residência 1 (TC), que pode estar relacionado à filtração no filtro do tipo 3P Technik_VF1. Porém, essa constatação não pode ser confirmada, pois não foram feitas coletas antes e depois da passagem pelos filtros.

Figura 9 - Temperatura das amostras de água coletadas

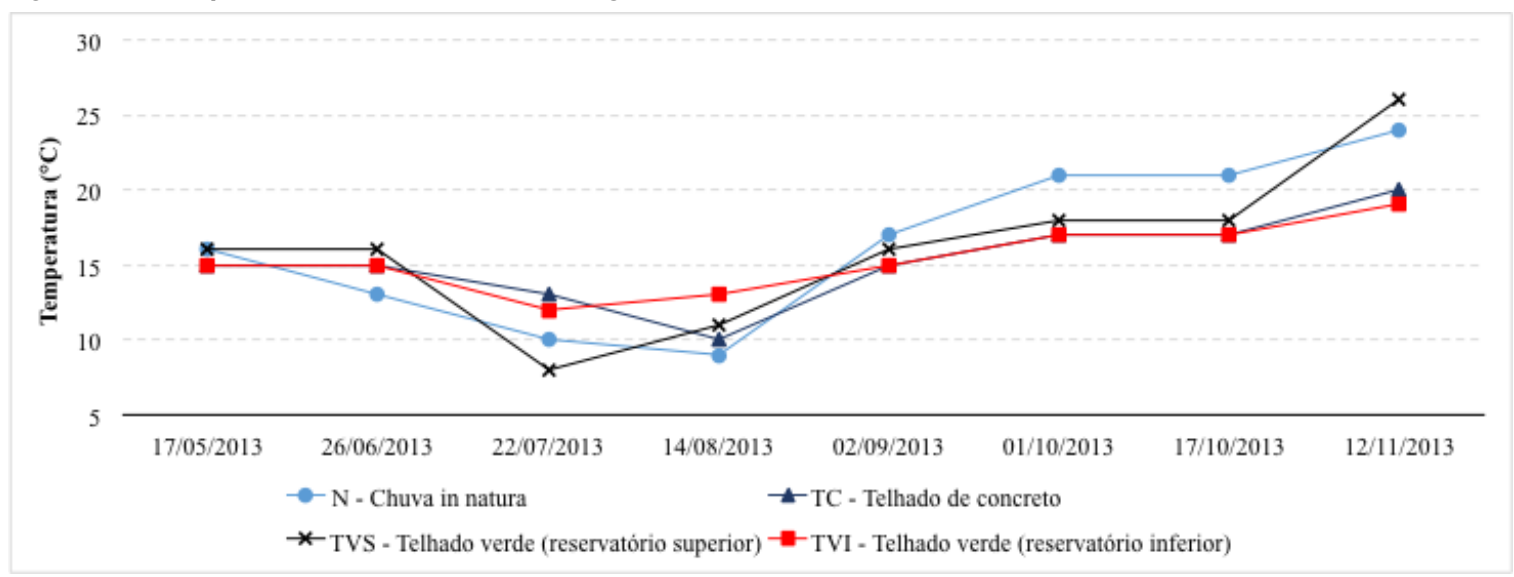

Figura 10 - Turbidez das amostras de água coletadas

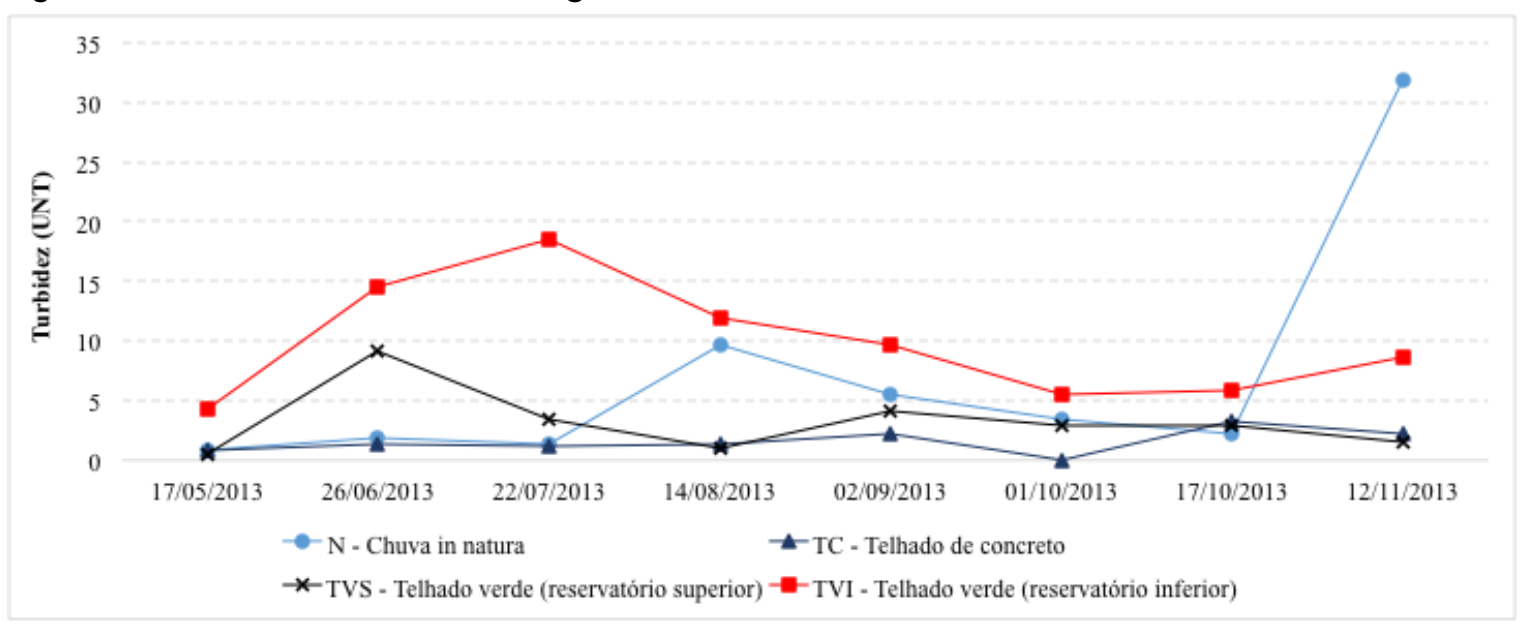


A análise estatística revelou a existência de diferenças significativas nos resultados médios de turbidez (p-valor 0,0372) entre as amostras coletadas, sendo as maiores variações de 8,3 UNT entre TVI e TC (9,86-1,56 UNT), 6,68 UNT entre TVI e TVS (9,86-3,18 UNT), 5,52 UNT (7,08-1,56 UNT) entre N e TC, 3,90 UNT (7,08-3,18 UNT) entre $\mathrm{N}$ e TVS, 2,78 UNT (9,86-7,08 UNT) entre $\mathrm{N}$ e TVI, e 1,62 (3,18-1,56 UNT) entre TVS e TC. Os valores máximos foram de 18,50 UNT no TVI, 9,10 UNT no TVS e 3,22 UNT no TC.

Foi possível concluir que $34 \%$ das amostras coletadas resultaram em turbidez inferior a 2,00 UNT, com predomínio no TC; e $65 \%$ em turbidez inferior a 5,00 UNT (uso para fins menos restritivos), que correspondem aos valores máximos definidos na NBR 15527 (ABNT, 2007) para esse parâmetro.

\section{$\mathrm{pH}$}

Os maiores valores de $\mathrm{pH}$, próximos da neutralidade, foram observados nas amostras coletadas tanto no reservatório superior quanto no inferior (TVS e TVI) na residência 2 com telhado verde. Esses valores estão de acordo com o reportado por Berndtsson, Emilsson e Bengtsson (2009), que indicam que a passagem da água da chuva por telhados verdes contribui para diminuição da acidificação da água nos reservatórios de água pluviais e nos corpos de água que recebem contribuição de efluentes pluviais urbanos.

Nas amostras coletadas da água da chuva in natura (N) foi observado caráter levemente ácido. Esse comportamento também foi notado nas amostras coletadas no reservatório da residência 1 (TC), porém menos acentuado, provavelmente devido à passagem da água pelo telhado de concreto (Figura 11).

A Anova revelou a existência de diferenças significativas entre as médias nos resultados de $\mathrm{pH}$ (p-valor 0,00004) e o teste de Tukey post-hoc indicou que a diferença média ocorreu entre $\mathrm{N}$ e TVI e entre $\mathrm{N}$ e TVS, com maiores variações de $1,15 \quad(6,96-5,81)$ e $1,10 \quad(6,91-5,81)$, respectivamente. Valores máximos demonstraram variação ligeiramente maior de 0,80 do TVS $(7,40)$ para $\mathrm{N}(6,60)$ e de 0,90 do TVI $(7,50)$ para $\mathrm{N}$ $(6,60)$.

Na NBR 15527 (ABNT, 2007) é estabelecida faixa de variação do $\mathrm{pH}$ de 6,0 a 8,0 para tubulações de aço carbono ou galvanizado, sem nenhuma menção ao PVC, que foi usado na residência 2 para as instalações de captação e aproveitamento de água da chuva.

\section{Oxigênio Dissolvido (OD)}

A variação temporal da concentração de oxigênio dissolvido (OD) foi de 7,4 a 14,3 mg/L, 4,9 a 12,8 $\mathrm{mg} / \mathrm{L}, 9,1$ a 14,2 mg/L e 7,6 a 13,6 mg/L em amostras coletadas no N, TC, TVS e TVI, respectivamente (Figura 12).

A Anova revelou a inexistência de diferenças nos resultados médios de OD entre as amostras analisadas (p-valor 0,4433), e a variação média de leituras foi de $11,5 \%$ entre $\mathrm{N}$ e TVS, $13,8 \%$ entre TC e TVS, e $12,3 \%$ entre TVS e TVI.

\section{Série nitrogenada}

Foram determinadas as concentrações do nitrogênio na forma de amônia, nitrito e nitrato em sete coletas. A presença de nitrogênio na água captada dos telhados verdes pode estar associada à presença de excrementos animais, bem como ao uso de fertilizantes. Porém, não há presença de animais na residência e não foi adicionado fertilizante ao solo durante a realização deste estudo.

Foi notada concentração de amônia inferior a 0,40 $\mathrm{mg} / \mathrm{L}$ (TVI) em $82 \%$ das amostras em todos os pontos, sendo observadas maiores concentrações apenas nas amostras de água da chuva in natura (1,01 a 2,25 mg/L) e do TVI $(0,90 \mathrm{mg} / \mathrm{L})$ (Figura 13). Os valores mais elevados no TVI na última análise possivelmente são resultantes de trabalho de jardinagem e movimentação do substrato, realizados nos dias $1^{\circ}$ e 2 de dezembro de 2013. A maior concentração de amônia na chuva in natura em 02/09/2013 não apresentou causa aparente, porém pode estar relacionada à exposição do pluviômetro por longos períodos de tempo.

A Anova revelou a inexistência de diferenças significativas nos resultados médios de nitrito ( $\mathrm{p}$ valor 0,1310) e nitrato (p-valor 0,0765) e diferenças significativas nos resultados médios de amônia (p-valor 0,00252). Nesse caso, o teste de Tukey post-hoc indicou que a diferença média ocorreu com maior variação entre as amostras do TC e $\mathrm{N}$ de $0,89 \mathrm{mg} / \mathrm{L}(0,91-0,12 \mathrm{mg} / \mathrm{L})$, TVS e $\mathrm{N}$ de $0,85 \mathrm{mg} / \mathrm{L}(0,91-0,06 \mathrm{mg} / \mathrm{L})$ e $0,65 \mathrm{mg} / \mathrm{L}$ entre $\mathrm{N}$ e TVI $(0,91-0,26 \mathrm{mg} / \mathrm{L})$. Valores máximos demonstraram variação maior de $2,10 \mathrm{mg} / \mathrm{L}$ das amostras $\mathrm{N}(2,30 \mathrm{mg} / \mathrm{L})$ para TVS $(0,10 \mathrm{mg} / \mathrm{L})$ seguidas de $2,00 \mathrm{mg} / \mathrm{L}$ para $\mathrm{TC}(0,30 \mathrm{mg} / \mathrm{L})$ e 1,40 $\mathrm{mg} / \mathrm{L}$ para TVI $(0,90 \mathrm{mg} / \mathrm{L})$. 
Figura 11 - pH das amostras de água coletadas

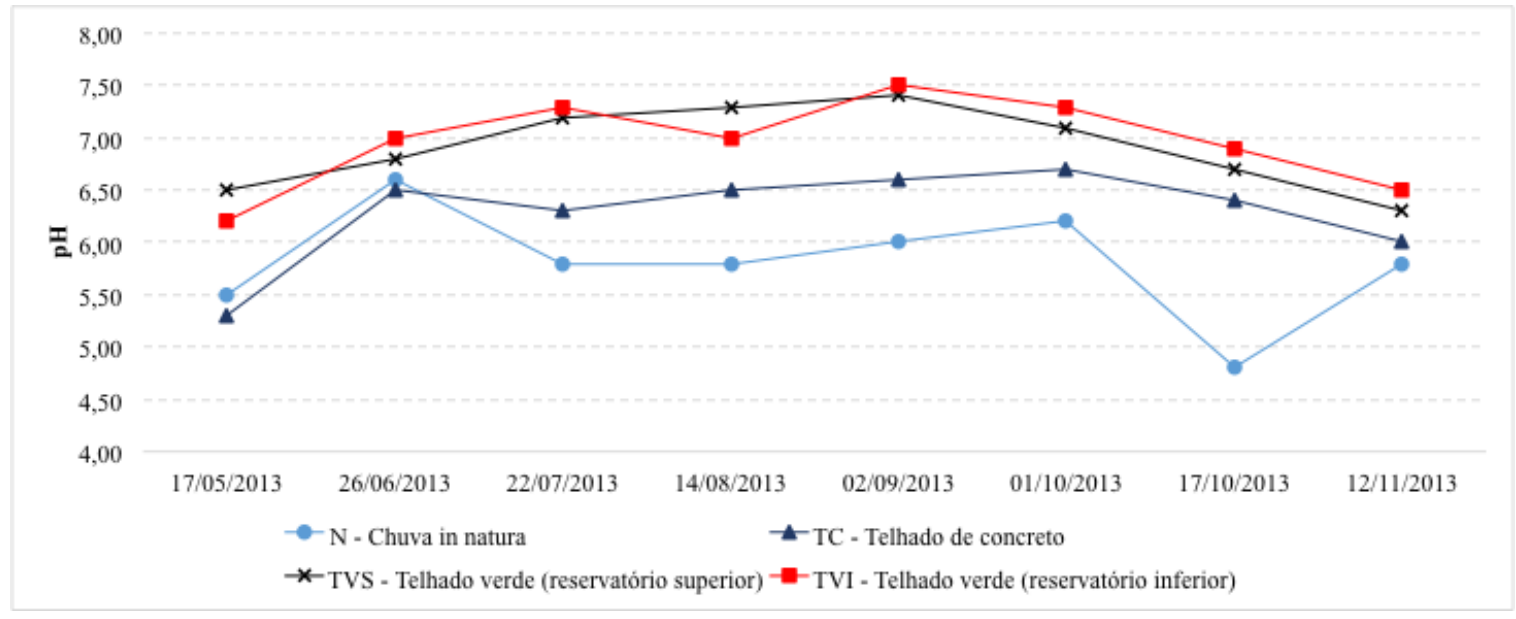

Figura 12 - Oxigênio dissolvido das amostras de água coletadas

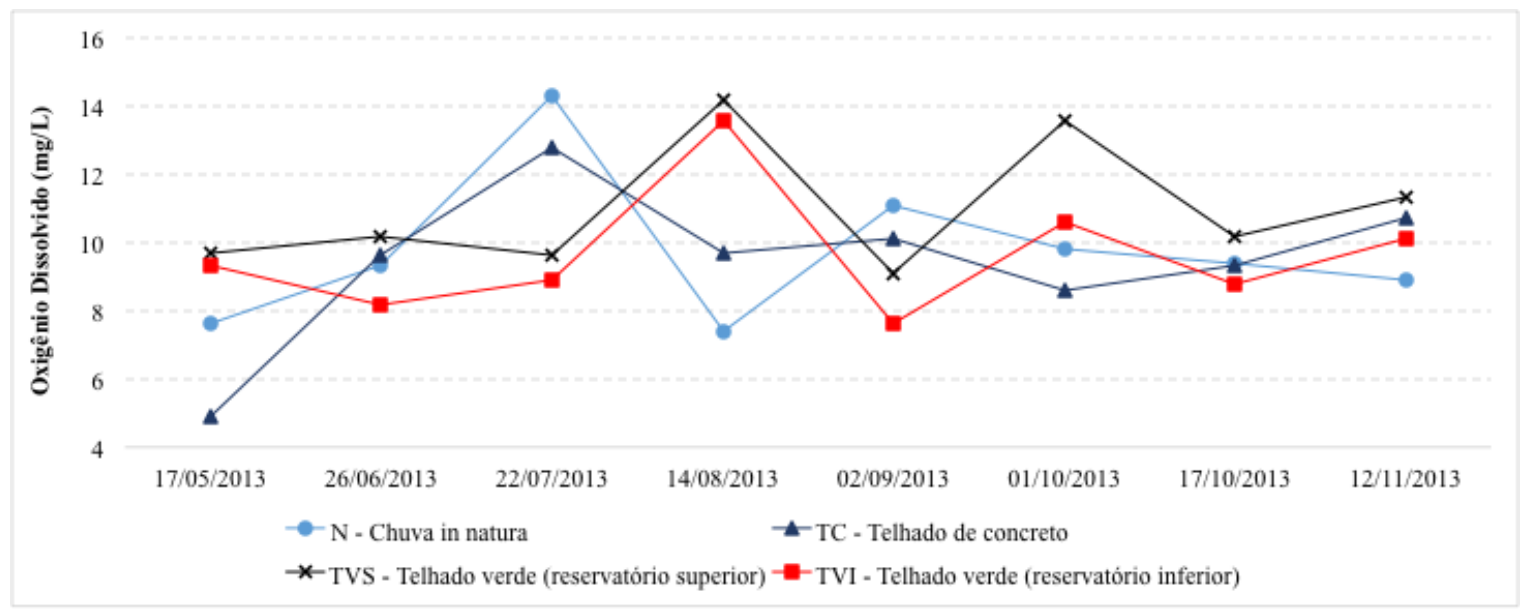

Figura 13 - Amônia das amostras de água coletadas

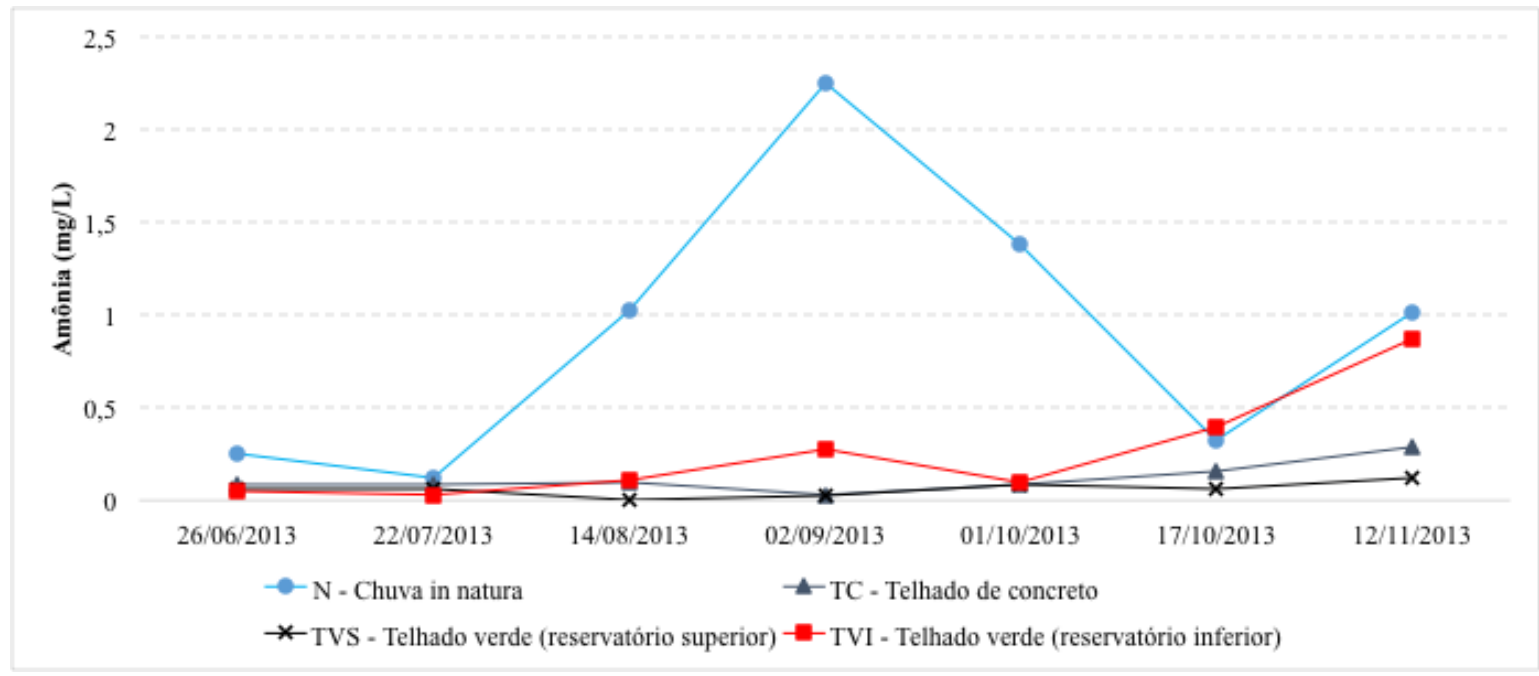


Os trabalhos de jardinagem também parecem ter contribuído para o aumento da concentração de nitrito tanto na amostra do TVI $(0,96 \mathrm{mg} / \mathrm{L})$ quanto no TVS $(0,34 \mathrm{mg} / \mathrm{L})$ no dia $12 / 11 / 2013$ (Figura 14). Nas demais amostras, as concentrações de nitrito resultaram próximas ao limite inferior de $0,07 \mathrm{mg} / \mathrm{L}$ no N. Foi verificado aumento nas concentrações de nitrito do $\mathrm{N}(<0,07 \mathrm{mg} / \mathrm{L})$ para TC $(0,01 \mathrm{mg} / \mathrm{L})$, TVS $(0,34 \mathrm{mg} / \mathrm{L})$ e TVI $(0,96$ $\mathrm{mg} / \mathrm{L})$, similar ao comportamento observado para a amônia.

Apesar de aproximadamente $79 \%$ dos resultados de nitrato serem inferiores ao limite mínimo de detecção de $0,50 \mathrm{mg} / \mathrm{L}$, foram obtidos valores elevados e iguais a 9,20 mg/L no TVI, $5,10 \mathrm{mg} / \mathrm{L}$ no TC e 2,30 mg/L no TVS (Figura 15).

Além disso, foi observada variação significativa dos valores nas amostras do TC e TVI, contrariando o reportado por Teemusk e Mander (2007) de que as diversas formas nitrogenadas tendem a diminuir nos telhados verdes à medida que atingem estabilidade.

As concentrações de nitrogênio na água de escoamento do telhado verde podem estar relacionadas ao tipo de solo ou à idade do telhado verde. No entanto, a investigação sobre a retenção de nitrato no telhado verde ainda é conflitante, pois estudos demonstram diminuição do nitrogênio total no escoamento do telhado verde, concentrações inalteradas, ou, ainda, aumento do nitrato e concentrações de nitrogênio total (BERNDTSSON; EMILSSON; BENGTSSON, 2009; GREGOIRE; CLAUSEN, 2011). Os resultados apresentados neste estudo não são conclusivos quanto ao comportamento da série nitrogenada.

Figura 14 - Nitrito das amostras de água coletadas

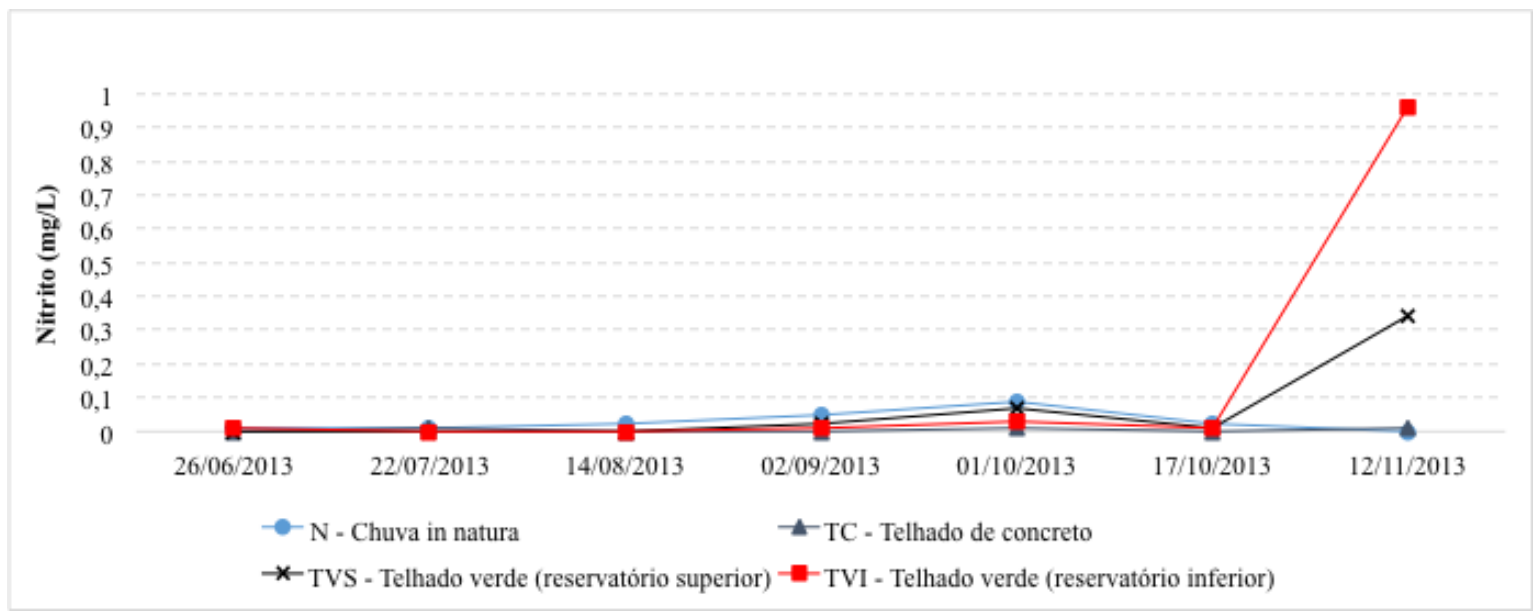

Figura 15 - Nitrato das amostras de água coletadas

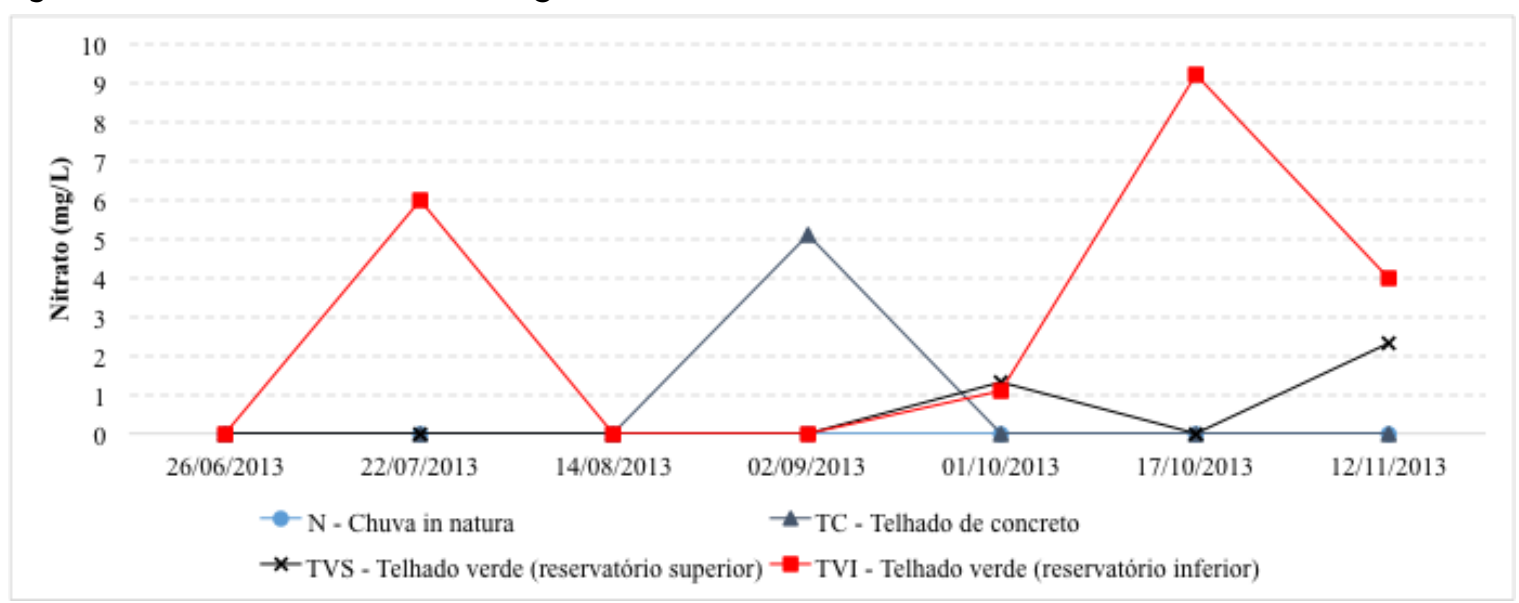

148 Teixeira, C. A.; Budel, M. A.; Carvalho, K. Q. de; Bezerra, S. M. da C.; Ghisi, E. 


\section{Fosfato}

Foi possível verificar concentrações mais elevadas de fosfato no TVI, provavelmente devido à presença do substrato do telhado verde e à lenta liberação do fosfato contido no solo pela lixiviação com a água da chuva (Figura 16). Esse comportamento foi previamente reportado por Macmillan (2011), Berndtsson, Emilsson e Bengtsson (2009), Hathaway, Hunt e Jennings (2008) e Gregoire e Clausen (2011).

Em função da variação nos resultados do fosfato e do tempo de condução deste estudo não foi possível atribuir o comportamento a algum fator isolado, ou seja, à presença de excrementos de pássaros, dentre outros poluentes, na água da chuva, ou à não liberação do fósforo nos telhados verdes conforme verificado por Berndtsson, Emilsson e Bengtsson (2009).

É possível notar aumento da concentração média de fosfato nas amostras de $6,57 \mathrm{mg} / \mathrm{L}$ no $\mathrm{N}$ para $7,39 \mathrm{mg} / \mathrm{L}$ no TC, $6,63 \mathrm{mg} / \mathrm{L}$ no TVS e 14,90 $\mathrm{mg} / \mathrm{L}$ no TVI. Os maiores valores foram obtidos no dia $02 / 09 / 2013$ de $22,70 \mathrm{mg} / \mathrm{L}$ no TVS e 28,90 $\mathrm{mg} / \mathrm{L}$ no $\mathrm{N}$, TC e TVI. Esses valores foram superados apenas no dia 01/10/2013 com 30,00 $\mathrm{mg} / \mathrm{L}$ no TVI.

A Anova revelou a inexistência de diferenças significativas nos resultados médios de fosfato ( $\mathrm{p}$ valor 0,39929). Valores máximos demonstraram variações nas amostras maiores de $23,43 \mathrm{mg} / \mathrm{L}$ no $\mathrm{N}, 22,61 \mathrm{mg} / \mathrm{L}$ no TC, $16,07 \mathrm{mg} / \mathrm{L}$ no TVS e 15,10 $\mathrm{mg} / \mathrm{L}$ no TVI.

\section{Demanda Química de Oxigênio (DQO)}

Foram observados menores valores de DQO nas amostras coletadas no TC da residência 1 , o que indica menores concentrações de matéria orgânica em decomposição. No TVS também foram obtidas menores concentrações em várias coletas, semelhante ao observado nas amostras da água da chuva in natura. No TVI foram notados valores mais elevados de DQO, o que indica a maior disponibilidade de matéria orgânica quando comparados aos outros pontos de coleta (Figura 17).

É possível notar aumento da DQO média de $\mathrm{N}$ para TVI (21,43 para 42,57 $\mathrm{mg} / \mathrm{L})$ e mais acentuadamente no TC e TVS para TVI $(17,00$ para $42,57 \mathrm{mg} / \mathrm{L})$. O maior valor de DQO foi obtido no TVI (86,00 mg/L).

A Anova revelou a inexistência de diferenças nos resultados médios de DQO entre as amostras analisadas (p-valor 0,1103). As maiores variações no valor médio da DQO foram de $25,71 \mathrm{mg} / \mathrm{L}$ entre TVI e TC (42,57-16,86 mg/L), 25,57 mg/L entre TVI e TVS (42,57-17,00 mg/L), 21,14 mg/L (42,57-21,43 mg/L) entre $\mathrm{N}$ e TVI, 4,57 mg/L (21,43-16,86 mg/L) entre $\mathrm{N}$ e TC, 4,43 mg/L (21,43- 17,00 mg/L) entre $\mathrm{N}$ e TVS, e $0,14 \mathrm{mg} / \mathrm{L}$ (17,00-16,86 mg/L) entre TVS e TC.

No TVS foram observados melhores resultados em termos de concentração de matéria orgânica durante o período amostrado, com mediana de 10 $\mathrm{mg} / \mathrm{L}$ e $75 \%$ das amostras com valor inferior a 28 $\mathrm{mg} / \mathrm{L}$. A análise da variação dos resultados é inconclusiva devido ao curto período de monitoramento. Porém, essa redução na DQO das amostras do TVS pode ser resultante da insuflação de ar decorrente do bombeamento da água. O monitoramento desse aspecto não foi investigado, mas é passível de futuras pesquisas.

No TVI foram notados os piores resultados dos pontos analisados com mediana de $45,00 \mathrm{mg} / \mathrm{L} \mathrm{e}$ valor máximo de $86,00 \mathrm{mg} / \mathrm{L}$ da concentração de matéria orgânica expressa em DQO. Foi observado que $75 \%$ das amostras resultaram inferiores a 67,50 mg/L.

Nos pontos $\mathrm{N}$ e $\mathrm{TC}$, as medianas resultaram em 20,00 e 13,00 mg/L, respectivamente, o que pode indicar que o telhado verde tem influência significativa no aumento da DQO, pois os valores das medianas para TVS e TVI foram superiores quando comparados às medianas de $\mathrm{N}$ e TC, como já mostrado anteriormente.

\section{Coliformes totais e termotolerantes}

Foi possível observar resultados elevados de coliformes totais nas amostras do TVI, conforme apresentado na Figura 18, principalmente nas amostras coletadas nos dias 27/06/2013 e $22 / 07 / 2013$, o que pode indicar contaminação pontual.

Na Figura 19 é possível notar relação direta do número de coliformes termotolerantes (E. coli) com o número de coliformes totais. Em concordância com outros parâmetros foram verificados valores comparativamente mais elevados nas amostras coletadas na residência 2 , com telhado verde, principalmente no ponto referente ao reservatório inferior (TVI).

$\mathrm{Na}$ Tabela 4 são apresentados os resultados das análises estatísticas de forma compilada de todos os parâmetros analisados (exceto coliformes), com os valores das médias, valores máximos e mínimos, desvios padrão e diferenças significativas. 


\section{Comparação com a legislação vigente}

Os dados obtidos foram comparados com a NBR 15527 (ABNT, 2007) (Tabela 5), que trata sobre os requisitos de aproveitamento da água da chuva de coberturas em áreas urbanas para fins não potáveis. A água da chuva captada nas duas residências é destinada à irrigação de jardins, limpeza de calçadas e descarga em bacias sanitárias.

Figura 16 - Fosfato das amostras de água coletadas

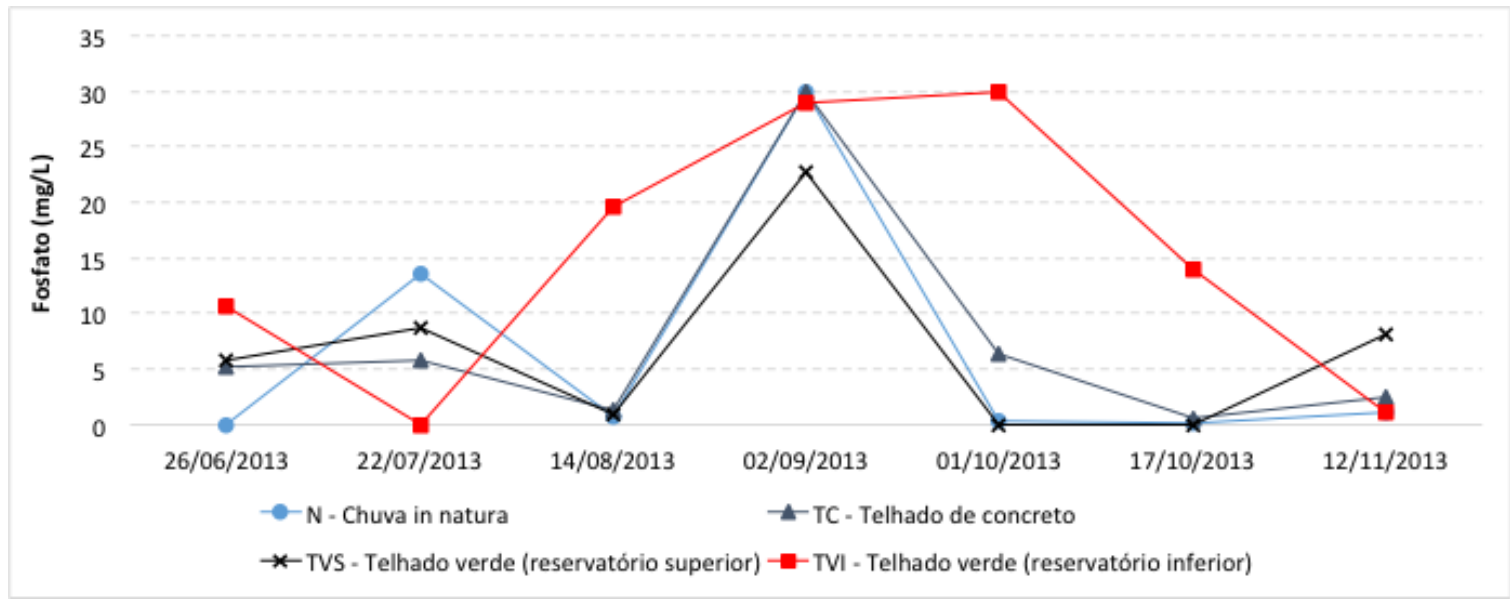

Figura 17 - DQO das amostras de água coletadas

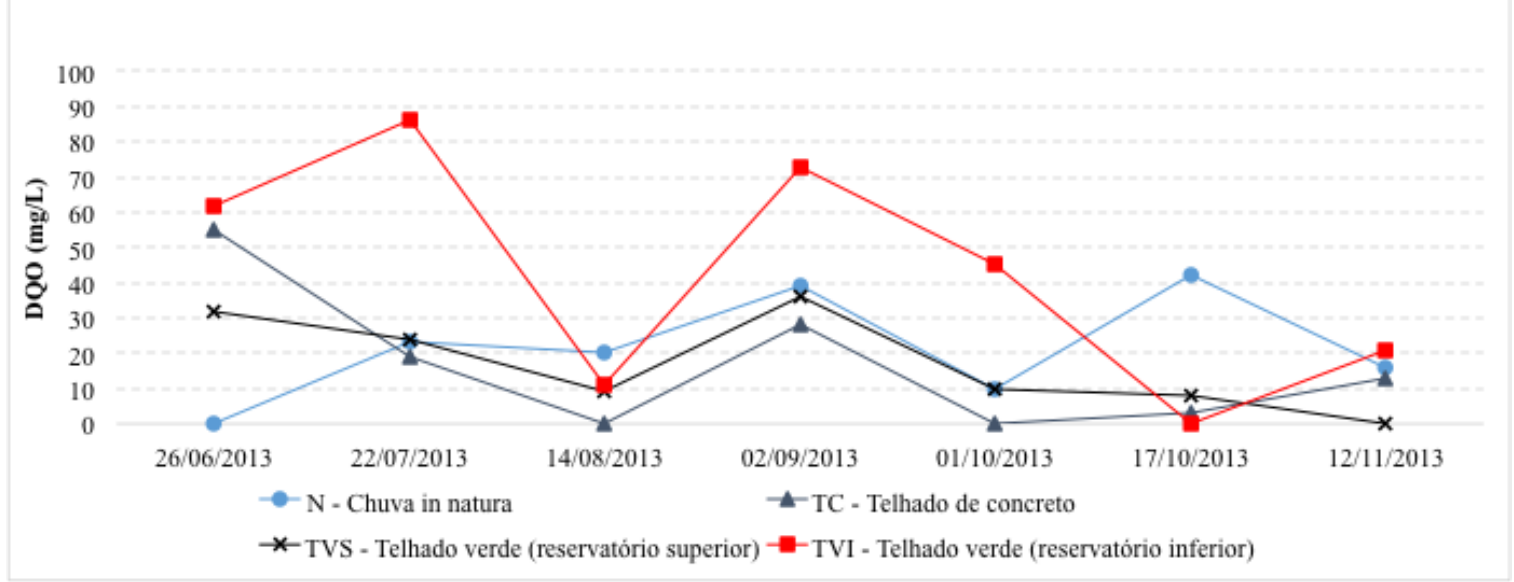

Figura 18 - Coliformes totais das amostras de água coletadas

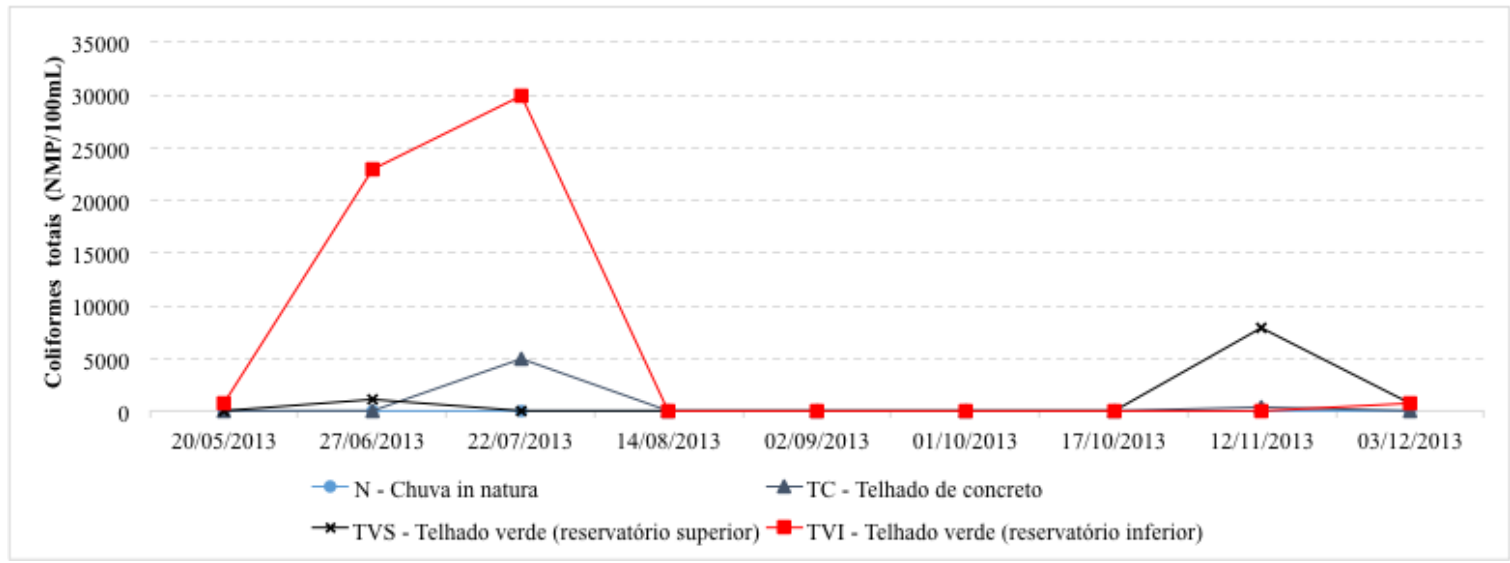

150 Teixeira, C. A.; Budel, M. A.; Carvalho, K. Q. de; Bezerra, S. M. da C.; Ghisi, E. 
Figura 19 - Escherichia coli das amostras de água coletadas

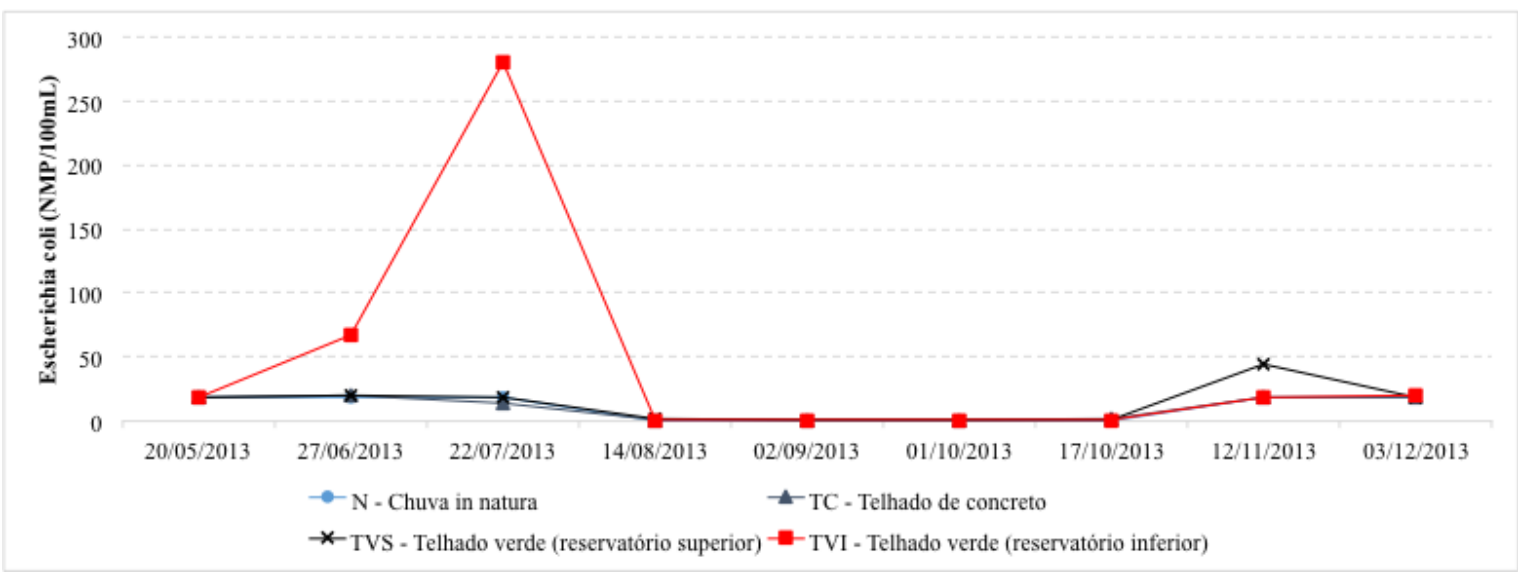

Tabela 4 - Resultados dos testes estatísticos aplicados para os dados obtidos na determinação dos parâmetros físico-químicos

\begin{tabular}{|c|c|c|c|c|c|c|c|c|c|c|}
\hline $\begin{array}{c}\text { Pontos } \\
\text { de } \\
\text { coletas }\end{array}$ & Parâmetro & $\begin{array}{c}\text { Temp. } \\
\left({ }^{\circ} \mathrm{C}\right)\end{array}$ & $\begin{array}{l}\text { Turb. } \\
\text { (UNT) }\end{array}$ & pH & $\begin{array}{c}\text { Amônia } \\
\text { (mg/L) }\end{array}$ & $\begin{array}{c}\mathrm{NO}_{2} \\
(\mathrm{mg} / \mathrm{L})\end{array}$ & $\begin{array}{c}\mathrm{NO}_{3} \\
(\mathrm{mg} / \mathrm{L})\end{array}$ & $\begin{array}{c}\mathrm{PO}_{4}{ }^{3-} \\
(\mathrm{mg} / \mathrm{L})\end{array}$ & $\begin{array}{c}\text { OD } \\
(\mathrm{mg} / \mathrm{L})\end{array}$ & $\begin{array}{c}\text { DQO } \\
(\mathrm{mg} / \mathrm{L})\end{array}$ \\
\hline \multirow{5}{*}{$\mathrm{N}$} & Média & 16,38 & 7,08 & 5,81 & 0,91 & 0,03 & $<0,50$ & 6,57 & 9,73 & 21,43 \\
\hline & Máx. & 24,00 & 31,80 & 6,60 & 2,25 & 0,09 & $<0,50$ & 30,00 & 14,30 & 42,00 \\
\hline & Mín. & 9,00 & 0,86 & 4,80 & 0,12 & $<0,01$ & $<0,50$ & $<0,50$ & 7,40 & $<10,00$ \\
\hline & DP & 5,45 & 10,39 & 0,52 & 0,76 & 0,03 & $<0,50$ & 11,44 & 2,19 & 15,03 \\
\hline & DS & $\mathrm{ns}$ & Ns & $\begin{array}{l}<\mathrm{TVS} \\
<\mathrm{TVI}\end{array}$ & $\begin{aligned} &>\mathrm{TC} \\
&>\mathrm{TVS} \\
&>\mathrm{TVI}\end{aligned}$ & ns & ns & ns & ns & $\mathrm{ns}$ \\
\hline \multirow{5}{*}{$\mathrm{TC}$} & Média & 15,25 & 1,56 & 6,29 & 0,12 & $<0,01$ & 0,73 & 7,39 & 9,46 & 16,86 \\
\hline & Máx. & 20,00 & 3,22 & 6,70 & 0,29 & 0,01 & 5,10 & 30,00 & 12,80 & 55,00 \\
\hline & Mín. & 10,00 & 0,02 & 5,30 & 0,03 & $<0,01$ & $<0,50$ & 0,60 & 4,90 & $<10,00$ \\
\hline & $\mathrm{DP}$ & 2,96 & 0,98 & 0,45 & 0,09 & 0,01 & 1,93 & 10,22 & 2,23 & 19,83 \\
\hline & DS & ns & $<\mathrm{TVI}$ & $\begin{array}{l}<\text { TVS } \\
<\text { TVI }\end{array}$ & $<\mathrm{N}$ & $\mathrm{ns}$ & $\mathrm{ns}$ & $\mathrm{ns}$ & ns & $<\mathrm{TVI}$ \\
\hline \multirow{5}{*}{ TVS } & Média & 16,13 & 3,18 & 6,91 & 0,06 & 0,06 & 0,51 & 6,63 & 10,99 & 17,00 \\
\hline & Máx. & 26,00 & 9,10 & 7,40 & 0,12 & 0,34 & 2,30 & 22,70 & 14,20 & 36,00 \\
\hline & Mín. & 8,00 & 0,55 & 6,30 & 0,00 & $<0,01$ & $<0,50$ & $<0,50$ & 9,10 & $<10,00$ \\
\hline & DP & 5,30 & 2,70 & 0,40 & 0,04 & 0,12 & 0,92 & 8,01 & 1,91 & 13,56 \\
\hline & DS & ns & Ns & $\begin{array}{l}>\mathrm{N} \\
>\mathrm{TC}\end{array}$ & $<\mathrm{N}$ & $\mathrm{ns}$ & $\mathrm{ns}$ & ns & ns & ns \\
\hline \multirow{5}{*}{ TVI } & Média & 16,38 & 9,86 & 6,96 & 0,26 & 0,15 & 2,90 & 14,90 & 9,64 & 42,57 \\
\hline & Máx. & 19,00 & $18,504,25$ & 7,50 & 0,87 & 0,96 & 9,20 & 30,00 & 13,60 & 86,00 \\
\hline & Mín. & 12,00 & 4,89 & 6,20 & 0,03 & 0,01 & $<0,50$ & $<0,50$ & 7,60 & $<10,00$ \\
\hline & DP & 2,12 & $>\mathrm{TC}$ & 0,43 & 0,30 & 0,36 & 3,63 & 12,07 & 1,87 & 32,84 \\
\hline & DS & ns & & $\begin{array}{r}>\mathrm{N} \\
>\mathrm{TC} \\
\end{array}$ & $<\mathrm{N}$ & ns & ns & $\mathrm{ns}$ & ns & ns \\
\hline
\end{tabular}

Nota: Legenda:

Temp. - temperatura $\left({ }^{\circ} \mathrm{C}\right)$;

Turb. - turbidez (UNT);

$\mathrm{NO}_{2}^{-}$- nitrito (mg/L);

$\mathrm{NO}_{3}^{-}$- nitrato $(\mathrm{mg} / \mathrm{L})$;

$\mathrm{PO}_{4}^{3-}$ - fosfato (mg/L);

Média - valor da média;

Máx - valor máximo;

Mín - valor mínimo;

DP - desvio padrão;

DS - diferenças significativas para maior $(>)$ ou menor $(<)$ em relação aos resultados médios nos pontos analisados; e

ns - não significativo. 
Tabela 5 - Comparação dos resultados com a ABNT NBR 15527:2007 - Requisitos de aproveitamento da água da chuva de coberturas em áreas urbanas para fins não potáveis

\begin{tabular}{|c|c|c|c|c|c|c|c|c|c|}
\hline \multirow[t]{2}{*}{ Parâmetro } & \multicolumn{2}{|c|}{$\begin{array}{l}\text { Água in } \\
\text { natura } \\
(\mathrm{N})\end{array}$} & \multicolumn{2}{|c|}{$\begin{array}{l}\text { Telhado com } \\
\text { telhas de } \\
\text { concreto } \\
\text { (TC) } \\
\end{array}$} & \multicolumn{2}{|c|}{$\begin{array}{l}\text { Telhado verde, } \\
\text { reservatório } \\
\text { superior } \\
\text { (TVS) }\end{array}$} & \multicolumn{2}{|c|}{$\begin{array}{c}\text { Telhado verde, } \\
\text { reservatório } \\
\text { inferior } \\
\text { (TVI) }\end{array}$} & \multirow{2}{*}{$\begin{array}{c}\text { Valor } \\
\text { estabelecido } \\
\text { na NBR } \\
15527 \\
\text { (ABNT, } \\
2007 \text { ) }\end{array}$} \\
\hline & Mín. & Máx. & Mín. & Máx. & Mín. & Máx. & Mín. & Máx. & \\
\hline$\overline{\mathrm{pH}}$ & 4,80 & 6,60 & 5,30 & 6,70 & 6,30 & 7,40 & 6,20 & 7,50 & $6,0-8,0$ \\
\hline $\begin{array}{l}\text { Turbidez } \\
\text { (UNT) }\end{array}$ & 0,86 & 31,80 & 0,02 & 3,22 & 0,55 & 9,10 & 4,25 & 18,50 & $\begin{array}{c}<2,0 \text { UNT } \\
<5,0 \text { UNT } \\
\text { para usos } \\
\text { menos } \\
\text { restritivos }\end{array}$ \\
\hline $\begin{array}{l}\text { Coliformes } \\
\text { totais } \\
(\mathrm{NMP} / 100 \\
\mathrm{mL})\end{array}$ & 1,1 & 23,0 & $<18,0$ & $4.900,0$ & $<18,0$ & $7.900,0$ & 0,0 & $30.000,0$ & $\begin{array}{l}\text { Ausência em } \\
\quad 100 \mathrm{~mL}\end{array}$ \\
\hline $\begin{array}{l}\text { E. Coli } \\
\text { (NMP/100 } \\
\mathrm{mL})\end{array}$ & 1,1 & 18,0 & 0,0 & $<18,0$ & 0,0 & 45,0 & 0,0 & 280,0 & $\begin{array}{l}\text { Ausência em } \\
100 \mathrm{~mL}\end{array}$ \\
\hline
\end{tabular}

É possível observar que os valores do $\mathrm{pH}$ das amostras de água captadas no telhado verde no reservatório superior e inferior (TVS e TVI) estão de acordo com o estabelecido na norma NBR 15527 (ABNT, 2007). A referida norma apresenta esse parâmetro para tubulações de aço carbono ou galvanizado, mas não para outros materiais. $\mathrm{O}$ valor do $\mathrm{pH}$ das amostras coletadas no telhado com telhas de concreto (TC) também é aceitável de acordo com o estabelecido na norma, com um único valor inferior ao limite mínimo. Porém, $62,5 \%$ dos valores de $\mathrm{pH}$ não atendem ao limite mínimo de 6,0 descrito na norma, com valores inferiores a esse valor nas amostras de chuva in natura $(\mathrm{N})$.

Quanto à turbidez, 37\% das amostras de chuva in natura $(\mathrm{N})$ e $62,5 \%$ das amostras coletadas no reservatório do telhado de concreto (TC) estão de acordo com o indicado de 2,0 UNT na NBR 15527 (ABNT, 2007).

A ausência de coliformes totais e de coliformes termotolerantes (E. coli) não foi verificada em nenhum dos pontos de captação avaliados em 100 $\mathrm{mL}$ de qualquer amostra, ou seja, não foi possível atender ao disposto na NBR 15527 (ABNT, 2007).

\section{Conclusões}

No estudo comparativo da qualidade da água da chuva coletada em duas residências em Curitiba, uma construída com telhado verde e a outra com telhado com telhas de concreto, foram obtidos dados e informações locais que indicam o não atendimento total da NBR 15527 (ABNT, 2007) para fins não potáveis.

Quanto aos resultados obtidos, a melhor qualidade no parâmetro turbidez foi verificada nas amostras de água coletadas no telhado com telhas de concreto (TC), de acordo com o estabelecido na NBR 15527 (ABNT, 2007). Valores de até 5,0 UNT para fins menos restritivos são mencionados na norma, porém sem explicitar quais seriam esses usos menos restritivos. Seria interessante, em algum momento de revisão dessa norma, que essa definição, ou exemplos do que seriam usos mais ou menos restritivos, fossem incluídos.

A concentração de nitrogênio foi avaliada na forma de amônia, nitrato e nitrito e foi maior nos reservatórios, superior e inferior, ligados ao telhado verde. Nos dois telhados foram obtidas concentrações elevadas de fosfato, e no telhado verde provavelmente devido ao substrato e à liberação do fosfato contido no solo.

As amostras coletadas no telhado verde apresentaram diminuição da acidez natural da água da chuva, portanto apresentaram qualidade superior no parâmetro $\mathrm{pH}$. As amostras coletadas no telhado com telhas de concreto apresentaram menor concentração de matéria orgânica, ou seja, apresentaram qualidade superior no parâmetro DQO.

Nos parâmetros microbiológicos, as amostras coletadas nos dois telhados não obtiveram qualidade suficiente para atender a NBR 15527 (ABNT, 2007), com maiores valores no telhado 
verde para coliformes totais e termotolerantes $(E$. coli).

Com a análise dos resultados conclui-se que, para completo atendimento da norma NBR 15527 (ABNT, 2007) para usos não potáveis, como proposto nas residências do estudo, seria necessária a instalação de um sistema de desinfecção para tratamento da água da chuva in natura e armazenada nos reservatórios. De fato, o rigor da norma quanto aos parâmetros microbiológicos pode até inibir o aproveitamento da água da chuva em algumas situações. Diante disso, recomenda-se ao comitê da NBR 15527 (ABNT, 2007) que as questões quanto ao rigor dos parâmetros microbiológicos sejam revistas no processo de revisão da norma.

Seria recomendado incluir na norma exemplos de usos mais ou menos restritivos, quanto ao parâmetro turbidez. Outra sugestão seria incluir parâmetros de monitoramento para OD e DQO, pois também caracterizam a qualidade da água da chuva e poderiam ser utilizados como indicadores da necessidade de limpeza do reservatório de armazenamento da água da chuva para usos não potáveis. Por fim, seria importante incluir parâmetros específicos de monitoramento de qualidade da água da chuva após passagem por telhados verdes, como por exemplo indicadores da série nitrogenada, que auxiliariam na definição adequada do uso da água da chuva e do descarte mais apropriado na rede de esgotamento sanitário ou de drenagem pluvial.

\section{Referências}

ASSOCIAÇÃO BRASILEIRA DE NORMAS

TÉCNICAS. NBR 9898: preservação e técnicas de amostragem de efluentes líquidos e corpos receptores. Rio de Janeiro, 1987.

\section{ASSOCIAÇÃO BRASILEIRA DE NORMAS} TÉCNICAS. NBR 15527: água de chuva: aproveitamento de coberturas em áreas urbanas para fins não potáveis: requisitos. Rio de Janeiro, 2007.

BERNDTSSON, J. C.; EMILSSON, T.; BENGTSSON, L. The Influence of Extensive Vegetated Roofs on Runoff Quality. Science of the Total Environment, v. 355, n. 1/3, p. 48-63, 2009.

BERNDTSSON, J. C. Green Roof Performance Towards Management of Runoff Water Quantity and Quality: a review. Ecological Engineering, v. 36, n. 4, p. 351-360, 2010.
BEZERRA, S. M. C. et al. Estudo do Programa de Conservação e Uso Racional da Água nas Edificações - PURAE, de Curitiba - Paraná e Alguns Exemplos de Sua Aplicação. In: CONGRESSO BRASILEIRO DE ENGENHARIA SANITÁRIA E AMBIENTAL, 25., Recife, 2009. Anais... Recife, 2009.

BEZERRA, S. et al. Políticas Públicas Para Conservação e Uso Racional de Água: Estudo de Caso do Município de Curitiba - Brasil. In: WORLD SUSTAINABLE BUILDING CONFERENCE, São Paulo, 2010. Anais... São Paulo, 2010a.

BEZERRA, S. et al. Dimensionamento de Reservatório Para Aproveitamento de Água de Chuva: Comparação entre Métodos da ANBT NBR 15527:2007 e Decreto Municipal 293/2006 de Curitiba, PR. Ambiente Construído, Porto Alegre, v. 10, n. 4, p. 219-231, out./dez. 2010 b.

BUDEL, M. A. Estudo Comparativo da Qualidade da Água de Chuva Coletada em Cobertura Convencional e em Telhado Verde. Curitiba, 2014. 124 f. Dissertação (Mestrado em Engenharia Civil) - Escola de Engenharia, Universidade Tecnológica Federal do Paraná, Curitiba, 2014.

BUZETI, J. C.; BEZERRA, S. M. C. Qualidade da Água Armazenada em Reservatórios de Água de Chuva em Edifícios Residenciais de Curitiba - PR. In: CONGRESSO BRASILEIRO DE ENGENHARIA SANITÁRIA E AMBIENTAL, 28., Rio de Janeiro, 2015. Anais... Rio de Janeiro, 2015.

BUZETI, J. C.; BEZERRA, S. M. C. Qualidade da Água de Chuva Armazenada em Reservatórios. Revista Hydro, v. 10, n. 111, p. 40-44, jan. 2016.

CASTRO, A. S. Uso de Pavimentos Permeáveis e Coberturas Verdes no Controle QualiQuantitativo do Escoamento Superficial Urbano. Porto Alegre, 2011. 142 f. Tese (Doutorado em Recursos Hídricos e Saneamento Ambiental) - Programa de Pós-Graduação em Recursos Hídricos e Saneamento Ambiental, Universidade Federal do Rio Grande do Sul, Porto Alegre, 2011.

CURITIBA. Lei Municipal no 10.785 , de 18 de setembro de 2003, que cria no município de Curitiba o Programa de Conservação e Uso Racional da Águas nas Edificações. Curitiba, 18 set. 2003. 
CURITIBA. Decreto n⿳0 293, de 22 de março de 2006, que regulamenta a Lei Municipal no 10.785 de 2003 e dispõe sobre os critérios do uso e conservação racional da água nas edificações e dá outras providências. Curitiba, 22 mar. 2006.

CURITIBA. Decreto no 212, de 29 de março de 2007, que aprova o Regulamento de Edificações do Município de Curitiba. Curitiba, 29 mar. 2007.

EATON, A. D. et al. Standard Methods for the Examination of Water and Wastewater. 21. ed. Washington: American Public Health Association, American Water Works Association and Water Environment Federation, 2005.

FORNARO, A.; GUTZ, I. G. R. Acid Deposition and Related Atmospheric Chemistry ate the São Paulo Metropolis, Brazil: Part II.

Contribution of formic and acetic acids. São Paulo, 2000.

GHAFFARIANHOSEINI, A. et al. State of the Art of Rainwater Harvesting Systems Towards Promoting Green Built Environments: a review. Desalination and Water Treatment, v. 57, n. 1, p. 95-104, 2015.

GREGOIRE, B. G.; CLAUSEN, J. C. Effect of a Modular Extensive Green Roof on Stormwater Runoff and Water Quality. Ecological Engineering, v. 37, n. 6, p. 963 -969, 2011.

GOOGLE EARTH. [Imagem]. Disponível em: <https://www.google.com/earth/>. Acesso em: 2013.

HASHEMI, S. S. G.; MAHMUD, H. B.; ASHRAF, M. A. Performance of Green Roofs With Respect to Water Quality and Reduction of Energy Consumption in Tropics: a review. Renewable and Sustainable Energy Reviews, v. 52, p. $669-679,2015$.

HATHAWAY, A. M.; HUNT, W. F.; JENNINGS, G. D. A Field Study of Green Roof Hydrologic and Water Quality Performance. Transactions of the ASABE, v. 51, n. 1, p. 37-44, 2008.

JAQUES, R. C. Qualidade da Água de Chuva no Município de Florianópolis e Sua Potencialidade Para Aproveitamento em Edificações. Florianópolis, 2005. 102 f. Dissertação (Mestrado em Engenharia Sanitária e Ambiental) - Escola de Engenharia, Universidade Federal de Santa Catarina, Florianópolis, 2005.

LEE, J. Y.; BAK, G.; HAN, M. Quality of RoofHarvested Rainwater: comparison of different roofing materials. Environmental Pollution, v. 162, p. 422-429, 2012.

MAACK, R. Geografia Física do Estado do Paraná. Curitiba: BADEP/UFPR/IBPT, 1981.
MACMILLAN, M. York University Rooftop Garden Storm Water Quantity and Quality Performance Monitoring Report. In: GREENING ROOFTOPS FOR SUSTAINABLE COMMUNITIES, Portland, 2004. Proceedings... Portland, 2011.

MAY, S. Estudo da Viabilidade do Aproveitamento de Água de Chuva para Consumo Não Potável em Edificações. Sãof Paulo, 2004. 159 f. Dissertação (Mestrado em Engenharia) - Escola Politécnica, Universidade de São Paulo, São Paulo, 2004.

MAY, S. Caracterização, Tratamento e Reuso de Águas Cinzas e Aproveitamento de Águas Pluviais em Edificações. São Paulo, 2009. 200 f. Tese (Doutorado em Engenharia) - Escola Politécnica, Universidade São Paulo, São Paulo, 2009.

MORGAN, S.; CELIK, S.; RETZLAFF, W. Green Roof Storm-Water Runoff Quantity and Quality. Journal of Environmental Engineering, v. 139, n. 4, p. 471-478, 2013.

MORQUECHO, R.; PITT, R.; CLARK, S. E. Pollutant Associations with Particulates in Stormwater. In: WORLD WATER \& ENVIRONMENTAL RESOURCES CONTRESS, 1.; WORLD WATER \& ENVIRONMENTAL RESOURCES CONTRESS,1., Alaska, 2005. Anais... Alaska, 2005.

OLAOYE, R. A.; OLANIYAN, O. S. Quality of Rainwater From Different Roof Material. International Journal of Engineering and Technology, v. 2, n. 8, p. 1413-1421, 2012.

PAIVA, R. P., et al. A preliminary study of the anthropogenic contribution to São Paulo rainfall. Fresenius Environmental Bulletin, v. 6, n. 9, p. 508-513, 1997.

RAZZAGHMANESHA, M.; BEECHAMA, S.; SALEMIBA, T. The Role of Green Roofs in Mitigating Urban Heat Island Effects in the Metropolitan Area of Adelaide, South Australia. Urban Forestry \& Urban Greening, v. 15, p. 89102, 2016.

ROCHA, Flávio R., et al. Wet Deposition and Related Atmospheric Chemistry in the Sao Paulo Metropolis, Brazil: part 1. major inorganic ions in rainwater as evaluated by capillary electrophoresis with contactless conductivity detection.

Atmospheric Environment, v. 37, p. 105-115, 2003.

TASSI, R. et al. Telhado Verde: uma alternativa sustentável para a gestão das águas pluviais. Ambiente Construído, Porto Alegre, v. 14, n. 1, p. 139-154, jan./mar. 2014. 
TEEMUSK, A.; MANDER, Ü. Rainwater Runoff Quantity and Quality Performance From a Greenroof: the effects of short-term events. Ecological Engineering, v. 30, n. 3, p. 271-277, 2007.

VIJAYARAGHAVAN, K. Green Roofs: a critical review on the role of components, benefits, limitations and trends. Renewable and

Sustainable Energy Reviews, v. 57, p. 740-752, 2016.

\section{Agradecimentos}

Os autores agradecem à Coordenação de Aperfeiçoamento de Pessoal de Nível Superior (Capes) pela concessão de bolsa de mestrado. Os autores também agradecem a valiosa contribuição dos revisores desta revista.

Celimar Azambuja Teixeira

Departamento de Construção Civil | Universidade Tecnológica Federal do Paraná | Av. Deputado Heitor de Alencar Furtado, 4900, Campo Comprido | Curitiba - PR - Brasil | CEP 81280-340 | Tel.: (41) 3373-0623 | E-mail: celimar@utfpr.edu.br

Marcel Aramis Budel

Departamento de Construção Civil | Universidade Tecnológica Federal do Paraná | Tel.: (41) 3279-4500 |

E-mail: marcelbudel@hotmail.com

Karina Querne de Carvalho

Departamento de Construção Civil | Universidade Tecnológica Federal do Paraná | Tel.: (41) 3279-4500 | E-mail: kaquerne@gmail.com

Stella Maris da Cruz Bezerra

Departamento de Construção Civil | Universidade Tecnológica Federal do Paraná | Tel.: (41) 3279-4537 | E-mail: stella.utfpr@gmail.com

\section{Enedir Ghisi}

Laboratório de Eficiência Energética em Edificações, Departamento de Engenharia Civil, Centro Tecnológico | Universidade Federal de Santa Catarina | Trindade | Caixa Postal 476 | Florianópolis - SC - Brasil | CEP 88040-900 | Tel.: (48) 3721-2115 |

E-mail: enedir@labeee.ufsc.br

\section{Revista Ambiente Construído}

Associação Nacional de Tecnologia do Ambiente Construído

Av. Osvaldo Aranha, $99-3^{\circ}$ andar, Centro

Porto Alegre - RS - Brasil

$$
\text { CEP } 90035-190
$$

Telefone: +55 (51) 3308-4084

Fax: +55 (51) 3308-4054

www.seer.ufrgs.br/ambienteconstruido

E-mail: ambienteconstruido@ufrgs.br 